\title{
Principios, criterios y propósitos de desarrollo sustentable para la redensificación en contextos urbanos informales
}

\author{
Principles, criteria and purposes of sustainable development for re-densification \\ in unplanned urban contexts \\ Princípios, critérios e propósitos de desenvolvimento sustentável para a redensificação \\ em contextos urbanos informais
}

\section{Juan José Castiblanco-Prieto \\ Fabián Adolfo Aguilera-Martínez}

Universidad Católica de Colombia, Bogotá (Colombia)

Facultad de Diseño, Programa de Arquitectura

Centro de Investigaciones CIFAR

Fabián Alonso Sarmiento-Valdés

Universidad La Gran Colombia, Bogotá (Colombia)

Facultad de Arquitectura

Castiblanco-Prieto, J. J., Aguilera-Martínez, F. A., \& Sarmiento-Valdés, F. A. (2019) Principios, criterios y propósitos de desarrollo sustentable para la redensificación en contextos urbanos informales. Revista de Arquitectura (Bogotá) 2I(I), 2I-33. doi: http://dx.doi.org//0.14718/RevArq.2019.21.I.I209

\author{
Juan José Castiblanco-Prieto \\ Arquitecto, Universidad Nacional de Colombia, Bogotá (Colombia). \\ Magíster en Hábitat, Universidad Nacional de Colombia, Bogotá \\ (Colombia). \\ (D) https://orcid.org/0000-000I-8977-0375 \\ juanjosecastiblanco@gmail.com / jjcastiblanco@ucatolica.edu.co
}

\section{Fabián Adolfo Aguilera-Martínez}

Arquitecto, Universidad Católica de Colombia, Bogotá (Colombia). Maestro en Proyectos para el Desarrollo Urbano (IBERO), Ciudad de México (México).

Candidato a Doctor en Diseño y Estudios Urbanos. Universidad

Autónoma Metropolitana Unidad Azcapotzalco (UAM), México

(D) https://orcid.org/0000-0002-9166-224X

urbaguileram@gmail.com / faaguilera@ucatolica.edu.co

Fabián Alonso Sarmiento-Valdés

Arquitecto, Universidad Nacional de Colombia

Magíster en urbanismo, Universidad Nacional de Colombia

(D) https://orcid.org/0000-0003-3460-1579

fabian.sarmiento@ugc.edu.co

\section{Resumen}

En el marco de la ciudad informal, técnicamente no planificada, generada por un crecimiento urbano desregulado sobre territorios de valor ambiental, $y$ con demandas insatisfechas en infraestructura y servicios urbanos; se planteó el objetivo de formular un modelo de principios, criterios y propósitos que, desde la lógica del desarrollo sustentable, permita delinear acciones de reestructuración urbana a partir de procesos de redensificación, con los cuales se logre un crecimiento urbano sustentable desde un enfoque de consolidación integral del territorio. La investigación parte de una revisión conceptual en torno a la relación entre hábitat y desarrollo sustentable; a partir de esta se formula el modelo de principios, criterios y propósitos para el hábitat sustentable, $y$, finalmente, plantea lineamientos de diseño a manera de requerimientos estratégicos para la formulación de proyectos de redensificación. El modelo planteado permite definir un deber ser que incorpora principios de habitabilidad, equidad y eficiencia para las actuaciones urbanas integrales en contextos informales y, a la vez, evidencia las posibilidades que su aplicación tiene en proyectos de redensificación.

Palabras clave: área de desarrollo; asentamiento humano; desarrollo integrado; desarrollo urbano; renovación urbana.

\begin{abstract}
Within the informal city, technically unplanned, and generated by deregulated urban growth on territories of environmental value, with unmet demands on infrastructure and urban services, the research set out to formulate a model of principles, criteria and purposes that, from the logic of sustainable development, allow the delineation of urban restructuring actions based on re-densification processes, with which sustainable urban growth can be achieved from an approach of integral consolidation of the territory. The research is based on a conceptual review about the relationship between habitat and sustainable development, based on the model of principles, criteria and purposes for sustainable habitat, and finally, it presents design guidelines as strategic requirements for the formulation of re-densification projects. The model proposed, allows to define a must be that incorporates principles of habitability, equity and efficiency for integral urban actions in informal contexts, and at the same time shows the possibilities that its application has in re-densification projects.
\end{abstract}

Key words: Development areas; human settlements; integrated development; urban development; urban renewal.

\section{Resumo}

No contexto da cidade informal, tecnicamente não planejada e gerada por um crescimento urbano desenfreado, sobre territórios de valor ambiental, com demandas insatisfeitas em infraestrutura e serviços urbanos, este texto tem como objetivo formular um modelo de princípios, critérios e propósitos que, da lógica do desenvolvimento sustentável, permitam delinear ações de reestruturação urbana a partir de processos de redensificação, com os quais seja possível um crescimento urbano sustentável sob o enfoque de consolidação integral do território. Esta pesquisa parte de uma revisão conceitual sobre a relação entre hábitat e desenvolvimento sustentável; a partir disso, é formulado o modelo de princípios, critérios e propósitos para o hábitat sustentável; finalmente, propõem-se lineamentos de desenho como forma de requisitos estratégicos para formular projetos de redensificação. O modelo proposto permite definir um dever ser que incorpora princípios de habitabilidade, equidade e eficiência para as ações urbanas integrais em contextos informais e, por sua vez, evidencia as possibilidades que sua aplicação tem em projetos de redensificação.

Palavras-chave: área de desenvolvimento; assentamento humano; desenvolvimento integrado; desenvolvimento urbano; renovação urbana.

\section{Introducción}

En el presente artículo se muestran algunos de los resultados del proceso de investigación realizado entre la Universidad Católica de Colombia y la Universidad la Gran Colombia, el cual se ha preocupado por reconocer las implicaciones que tienen los procesos de redensificación en áreas informales de la ciudad contemporánea. Allí, su potencialidad para dar respuesta a la demanda de vivienda e infraestructura urbana derivada del intenso proceso de crecimiento demográfico en las ciudades se ha limitado al aumento de unidades de vivienda por área, y ha desaprovechado las posibilidades que este tipo de procesos tiene para generar transformaciones positivas integrales en el hábitat urbano. Los resultados que aquí se presentan están asociados al objetivo de definir lineamientos para la redensificación de sectores urbanos de origen informal, desde la perspectiva del desarrollo sustentable, como marco para garantizar el equilibrio entre las condiciones ambientales, sociales y económicas que el territorio ofrece a sus habitantes.

En este sentido, la hipótesis que orientó este trabajo se plantea en función de la definición e incorporación de requerimientos estratégicos de diseño para los proyectos de redensificación en áreas informales, con los cuales sea posible llevar a la práctica, de manera concreta, las discusiones y orientaciones generales planteadas desde el discurso del desarrollo sustentable en su aplicación a la transformación integral del territorio, a fin de garantizar condiciones adecuadas de calidad de vida para sus habitantes.

Reconocemos que la ciudad contemporánea es quizá la creación humana más compleja, no solo por su tamaño y diversidad, sino por los procesos múltiples y simultáneos que en ella ocurren 
durante su continuo crecimiento y desarrollo, y que la planificación urbana, desde los albores de la Modernidad, se ha valorado como proceso racional y técnico, mediante el cual se logra materializar una visión de ciudad a partir de la formulación de acciones concretas, orientadas precisamente a controlar dicha complejidad, en medio de un proceso continuo de crecimiento y transformación. A pesar de ello, y aunque la planificación tiene entre sus objetivos facilitar un adecuado funcionamiento e interacción de los diferentes sistemas urbanos, garantizar condiciones adecuadas de habitabilidad para sus ciudadanos, y lograr una estructura física y espacial apropiada para el desarrollo de actividades productivas, su correcta aplicación no ha impactado en la totalidad de las áreas urbanas que conforman las ciudades.

Por ello, amplias áreas urbanas, a las que nos referiremos como informales, fueron desarrolladas, construidas y consolidadas en el tiempo, fuera de las lógicas de la planificación, mediante procesos alejados de la técnica, desarticulados de los sistemas urbanos y de sus planes, proyectos e inversiones, donde la parcelación y la construcción de la vivienda ha ocurrido antes que el desarrollo de la infraestructura y los servicios que la deben soportar (Torres, 2009a). Por esto, aunque la ciudad de origen informal comparte un mismo territorio con la planificada, está segregada de su oferta de bienes y servicios, y presenta gran dificultad para integrarse funcional y productivamente con su entorno.

La existencia y reproducción de las deficientes condiciones de habitabilidad, productividad, oferta de servicios urbanos y articulación funcional de estas áreas urbanas informales se ha dado, además, en el marco de un proceso de urbanización global donde este tipo de desarrollos no planificados técnicamente son la alternativa de incorporación a la ciudad para muchas personas que día a día llegan a las ciudades, sobre todo en aquellos países categorizados como menos desarrollados (ONU-Hábitat, 2016).

Este proceso de urbanización generalizado a lo largo del planeta, donde la concentración de la población urbana aumenta en comparación con la población rural, tiene unas cifras que demandan de las entidades públicas, la academia, las organizaciones sociales y la sociedad en su conjunto pensar y actuar para dar respuestas adecuadas a los múltiples impactos que este fenómeno conlleva en lo ambiental, lo social, lo político, lo económico y lo físico-espacial ${ }^{1}$.

Es en este escenario de aumento y concentración de la población urbana, donde una porción importante de los nuevos habitantes se enfrentan

1 Específicamente en el contexto latinoamericano, y según datos de Naciones Unidas (United Nations, 2014), el proceso de urbanización ha generado un incremento de la población urbana entre 1990 y 2014 que pasó del 58 al 70\%, con proyecciones al año 2050 de un $86 \%$. Para Colombia, estas cifras se encuentran entre el 68 y $76 \%$ para los mismos años, y una proyección del $84 \%$ de población urbana para el 2050. a la decisión de entrar al mercado formal y planificado de la vivienda, costoso y burocratizado, o ubicarse en áreas informales ${ }^{2}$, donde pueden tener mejores posibilidades de asequibilidad, por temas de costo, forma de pago, área de lote, y la posibilidad que estos ofrecen para desarrollar una construcción progresiva que permita lograr, con el paso del tiempo, mejores condiciones para su vivienda (Carvajalino, 2013; Fique, 2009). De esta manera, la informalidad resulta favorable, no solo por estos temas relacionados con el acceso y la propiedad, sino también porque en estos sectores los nuevos pobladores encuentran estructuras barriales adaptadas a sus formas de vida y a sus redes sociales, familiares, económicas, además de otros capitales intangibles, que hacen de esta una opción competitiva y real en la decisión de elegir un lugar dónde asentarse en la ciudad (Saldaña, 2016).

Samuel Jaramillo (2012), al analizar lo que denomina la perspectiva de izquierda de la teoría de la marginalidad, menciona otros de los rasgos positivos que ofrecen las áreas informales en el acceso a soluciones habitacionales para sectores poblacionales con condiciones socioeconómicas precarias. Entre estas están: el aprovechamiento de la fuerza de trabajo propia, las condiciones de progresividad que permiten financiar de manera diferida los costos de la vivienda, la posibilidad de adaptarse en el tiempo a las diferentes formas de composición familiar, la posibilidad de procurarse ingresos adicionales en la vivienda mediante el alquiler o la disponibilidad de espacios para la realización de actividades productivas, y la posibilidad de crear movilización colectiva y desarrollo político entre los pobladores, generando su promoción como ciudadanos organizados.

A pesar de estas situaciones que pueden resultar ventajosas, son muchas y profundas las dificultades que evidentemente se presentan en estos sectores de origen informal, las cuales generan impactos negativos tanto en las condiciones de vida de sus habitantes como en el funcionamiento y la calidad urbana de la ciudad en general.

Por la naturaleza espontánea de la autoconstrucción, propia del desarrollo de estas áreas, no cuentan con estándares mínimos de seguridad y habitabilidad ni en la vivienda ni en su entorno, y presentan diversos y costosos problemas en las construcciones e infraestructuras (Jaramillo, 2012). Allí también son recurrentes y profundamente lesivos para la calidad de vida de los pobladores la falta de provisión de servicios públicos, la

2 Según datos de libre acceso del Banco Mundial (abril de 2018), aunque en la categoría Population living in slums hay una disminución del porcentaje de habitantes urbanos que viven en áreas urbanas irregulares (slums), los valores reales de la población afectada por esta condición siguen siendo muy altos. La comparación de los datos para los años 1990 y 2014 correspondientes al conjunto de países de ingreso mediano (entre los cuales se encuentra Colombia), muestra una disminución del 46 al $27 \%$ de la población urbana que vive en áreas urbanas irregulares. Puntualmente para Colombia, los valores para estos años son de 31 y $13 \%$ respectivamente. 
ausencia o las precarias condiciones en las redes e infraestructuras, la desventajosa ubicación en lugares periféricos lejanos del acceso a bienes de consumo, servicios y mercado laboral, y la mala calidad en la movilidad urbana y el transporte público.

De la misma manera, estos sectores presentan dificultades en el acceso a equipamientos de educación, de salud y aquellos en los cuales realizar actividades culturales y sociales (Techo, 2015), cuya ausencia por lejanía o falta de disponibilidad afecta no solo las condiciones de calidad de vida de los pobladores, sino también las posibilidades que tienen de superarlas mediante la capacitación y la formación, o por la asociación y participación en espacios que permitan el uso productivo del tiempo libre, el encuentro, la formación de redes sociales y la participación comunitaria.

Por otro lado, por sus condiciones de localización, muchas veces están expuestas a situaciones de riesgo natural y antrópico, por eventos de inundación, remoción en masa, contaminación por deshechos, incendios u otros accidentes asociados a la cercanía a áreas industriales, o por daños causados por la exposición a redes de alta tensión (Techo, 2015). También a nivel social, estas áreas habitadas por comunidades en extremas condiciones de pobreza muestran altas tasas de desempleo, criminalidad y violencia, y se enfrentan a un escenario, muchas veces controlado por actores ilegales en tensión, donde la violencia y la ausencia o debilidad del Estado son el marco de lo que Torres (2009b) define como la cultura de la simple supervivencia.

Por todo lo anterior, las áreas urbanas informales demandan una atención desde una dimensión ética y estética que reclama asumir que las formas de vida que allí tienen lugar niegan la condición básica de lo humano, e impiden que exista un escenario democrático donde las necesidades y los derechos de todos valgan por igual, ya que como lo manifiesta Torres:

\footnotetext{
... el derecho elemental a una vida digna no se ejerce cuando se vive en la miseria, bajo la coacción, entre el fuego cruzado, aislado de los servicios de bienestar, excluido de la educación y, todavía en muchas ciudades, de servicios públicos como el agua potable y la energía. Es decir, no se puede concebir la llamada democracia sin que existan verdaderos procesos de inclusión de todos los seres humanos presentes en el territorio, en el caso de las ciudades, sin posibilidades de acceso y disfrute de una canasta mínima de bienes y servicios que les garantice una calidad de vida urbana en condiciones de dignidad y equidad (2009b, p. 8).
}

Se requiere entonces configurar una perspectiva integral para el mejoramiento de las áreas urbanas informales en general, y específicamente, en nuestro caso, para los procesos de redensificación, donde se entienda la estrecha y dinámica interrelación entre las diferen- tes dimensiones del territorio de manera que se aborde efectivamente toda su complejidad.

Para el estudio marco del presente documento, así como para la revisión de estudios previos, se ha trabajado en la ciudad de Bogotá por su representatividad como capital de país, por su tamaño y complejidad, y por la alta presencia de áreas informales que han caracterizado su crecimiento y consolidación en las diferentes etapas de su desarrollo (Jiménez y Torres, 2014).

Entre estos estudios previos, que han abordado el proceso de redensificación en Bogotá desde sus efectos integrales en el territorio y la sociedad, se destacan los realizados por Rincón (2004), quien identifica las diferentes modalidades de este proceso, su relación con el nivel social de los habitantes y los efectos que tiene en su calidad de vida ${ }^{3}$. El autor reconoce específicamente que para las áreas de origen informal el proceso se ha concretado mediante la creación de inquilinatos al interior de los inmuebles, el desarrollo progresivo de la vivienda mediante el incremento del área ocupada en los lotes, y los procesos de renovación urbana. Las afectaciones para los habitantes en los dos primeros casos son el hacinamiento y la precariedad de las viviendas, la mínima provisión del espacio público y los equipamientos, el incremento de la demanda del transporte urbano, la ausencia de vegetación y áreas verdes, y el aumento del riesgo de inundaciones causado por la disminución de la capacidad de drenaje del terreno.

Por otro lado, frente a la densificación por renovación urbana, el autor señala que cuando esta se desarrolla sobre áreas de origen informal, por tratarse de una operación que se realiza para cambiar completamente la estructura urbana de áreas degradadas, genera el desplazamiento de los habitantes originales ubicados en áreas centrales, los cuales son reemplazados por habitantes de mejores condiciones socioeconómicas.

El estudio de Rincón (2004) concluye que el crecimiento de la ciudad por redensificación debe hacerse modificando las modalidades que hasta la fecha han predominado en Bogotá, pues comprueba que estas, aunque han aumentado la densidad de habitantes por área, han generado bajos niveles de calidad de vida en sectores de población con menores ingresos.

Otro de estos estudios es el realizado por Yunda (2019), quien al analizar las relaciones entre estratificación socioeconómica y densificación urbana

\footnotetext{
3 Las siete modalidades del proceso de redensificación identificadas por Rincón (2004) son: 1) densificación por demolición individual de inmuebles para ser sustituidos por otros de mayor altura; 2) densificación por subdivisión predial en lotes más pequeños; 3 ) densificación por consolidación de barrios de desarrollo progresivo mediante ampliación del módulo inicial y subarriendo parcial de áreas; 4) densificación por subdivisión y conformación de inquilinatos; 5) densificación por construcción de lotes vacíos al interior de las manzanas; 6) densificación por programas de renovación urbana de promoción privada o pública; 7) densificación por programas de cambio de uso y reutilización de edificaciones existentes.
} 
también evidencia las consecuencias negativas del aumento de la densidad en las modalidades de crecimiento predio a predio, renovación urbana y desarrollo. Así, la densificación, al ser estimulada primordialmente por la generación de renta sobre la base del máximo aprovechamiento del suelo, generan diversos efectos negativos, entre los cuales se cuentan la saturación de las redes de servicios públicos, el aumento del tráfico vehicular y la presión por calles, plazas y parques adicionales, los cuales, al no ser atendidos adecuadamente, afectan la calidad de vida de los residentes vecinos de estos sectores, y transfieren sus costos a ellos y al resto de la ciudad.

En la misma línea, Jiménez y Torres (2014) reconocen la prevalencia de los intereses particulares en el aumento de la densidad urbana, los cuales están por encima de cualquier iniciativa de planificación racional en perjuicio de las condiciones de calidad de vida de los ciudadanos, y concluyen que, aunque la ciudad de Bogotá coincide con el modelo de ciudad densa y compacta, este se ha concretado a costa de la insatisfacción de sus habitantes. Llaman la atención sobre la ineficiente movilidad que caracteriza los sectores de menores ingresos, ubicados muy lejos de los centros de productividad y empleo, así como por la ausencia de equipamientos y espacio público. Finalmente, los autores consideran que es necesario revalorizar la proximidad y la accesibilidad como satisfactores del derecho a la ciudad para lograr una reconversión democrática de las urbes latinoamericanas.

Dentro de este escenario, este estudio se enfoca en el proceso de aumento de la densidad por la vía de la renovación, como oportunidad para transformar de manera integral las condiciones urbanas de las áreas informales, puesto que como lo indica Rueda (2007), los procesos de redensificación, desde la lógica del modelo de ciudad sostenible y compacta, generan nuevas estructuras de ocupación del suelo, más eficientes y de mejor calidad habitacional para los pobladores de estas áreas. De esta manera, mediante la formulación de lineamientos de diseño, apoyados en un sistema de principios, criterios y propósitos de desarrollo sustentable para el hábitat informal, se busca hacer frente a la dispersión, segregación, baja densidad, ineficiencia y bajas condiciones de habitabilidad, que son causados por el uso desequilibrado del suelo urbano en las áreas informales de las ciudades latinoamericanas (Onu-Habitat, 2012).

Dentro de los lineamientos de la ciudad compacta aplicables a nuestra propuesta cabe enunciar los siguientes (Rueda, 2007): la lógica de un uso eficiente del suelo urbano como recurso; la valoración de las preexistencias urbanas en diálogo con los procesos de reestructuración y aumento de ocupación; la concepción del espacio público como eje central de la oferta urbana desde su vocación de espacio para la convivencia, el encuentro y la creatividad; la renaturalización como meta fundamental para equilibrar las relaciones del medio antrópico y el natural; la mixtura de usos como principio de la vitalidad urbana, el urbanismo de proximidad y la mejorara en el acceso a bienes y servicios; la incorporación de procesos de metabolismo urbano en relación con el aprovechamiento de recursos naturales y energías renovables, así como la gestión adecuada del ciclo urbano del agua y de los desperdicios; la promoción de valores como la autonomía, la responsabilidad y la accesibilidad incluyente en la población, y la cultura de la movilidad sostenible orientada a fortalecer el transporte público y los medios de transporte no contaminantes.

Como se desarrolla más adelante, estos lineamientos son útiles desde la lógica de la propuesta, como referentes para la formulación y aplicación de requerimientos estratégicos de desarrollo sustentable para el diseño arquitectónico y urbano, para proyectos de redensificación en los contextos urbanos que nos ocupan.

A continuación se presenta la metodología, donde se definen los alcances y procesos desarrollados para las etapas de conceptualización; formulación de principios, criterios y propósitos para la redensificación de las áreas urbanas informales; y propuesta de lineamientos de diseño. Posteriormente, se presentan los resultados de cada una de estas etapas, $y$, finalmente, junto con las conclusiones, se desarrolla la discusión que se centra en el valor de la redensificación como mecanismo de transformación integral de las áreas urbanas informales.

\section{Metodología}

El trabajo se desarrolla a partir de la conceptualización en torno al hábitat y el desarrollo sustentable, como marco para la resignificación y reformulación de los alcances en los procesos de redensificación para las áreas urbanas informales, así como para la definición de los principios del modelo que se plantea en el apartado siguiente. Para el concepto hábitat se seleccionaron autores provenientes de diferentes disciplinas que, desde una perspectiva compleja, abordan este concepto de manera relacional y no objetual. Por su parte, para el de desarrollo sustentable, se trabaja desde un enfoque latinoamericano que se centra en el alcance de la calidad de vida de manera integral.

Posteriormente, y apoyados en la conceptualización anterior, se formula el sistema de principios, criterios y propósitos sobre la base de la comparación de tres sistemas de indicadores de medición de la sostenibilidad urbana que fueron seleccionados por sus coincidencias conceptuales frente a nuestra perspectiva integral del desarrollo urbano sustentable: la iniciativa Ciudades emergentes y sostenibles del BID (2013), el índice de calidad de vida urbana (Leva, 2005), y la propuesta de política ambiental Biomanizales (Marulanda, 2000). Se eligieron también por su 
amplio desarrollo y su representatividad en contextos geográficos y políticos complementarios: la primera de ellas procede de un organismo multilateral de cooperación para el desarrollo, de carácter internacional, y las otras dos, de centros de investigación adscritos a universidades, una del contexto latinoamericano y otra del contexto nacional.

Finalmente, y con base en la propuesta de principios, criterios y propósitos, se formulan y sistematizan una serie de lineamientos de diseño arquitectónico y urbano, que se presentan a manera de requerimientos estratégicos para ser tenidos en cuenta en la formulación de proyectos de redensificación para el desarrollo sustentable de las áreas urbanas informales.

\section{Resultados}

\section{Los conceptos de hábitat y desarrollo sustentable como marco para la redensificación en áreas urbanas vulnerables}

Al utilizar el concepto de hábitat para aproximarse y comprender las dinámicas propias de la ciudad informal, es necesario reconocer la condición dinámica y relacional. Desde allí, el hábitat no se puede entender como una entidad fija ni aislada, por el contrario, más que su condición física y material interesa valorar la condición de relación, de acontecimiento y de proceso.

Así, el concepto de hábitat lo entendemos como una relación dinámica entre la sociedad y la naturaleza. Sociedad que agrupa todas aquellas realidades de múltiples dimensiones de carácter histórico, político, económico y cultural propias de la interacción entre individuos que actúan y viven en comunidad. Y naturaleza, desde un sentido amplio, entendida como el ambiente natural y antrópico, la estructura física de soporte en donde la sociedad desarrolla sus actividades y desenvuelve su vida.

El hábitat es, entonces, asumido como un proceso en permanente cambio que involucra de manera simultánea el espacio y las formas de vida, vincula directamente la acción del habitar, y en tanto proceso y relación, plantea un diálogo permanente de doble vía entre este y la vida que ocurre en su interior. Como lo anota Sánchez, esta mirada implica

... pasar de una concepción mecanicista a un paradigma complejo de la vida, del reloj como metáfora de la realidad al de la vida como modelo de una realidad compleja, evolutiva y autorregulada. Esta última visión se corresponde con la comprensión que viene desarrollando el pensamiento complejo o pensamiento sistémico, que nos permite afirmar que el hábitat no es una cosa, un objeto, sino un fenómeno procesual y fluido en permanente cambio, un sistema de procesos que implican interacciones dinámicas entre el ser humano y su mundo (2009, p. 119).
Esta perspectiva procesal y relacional del concepto de hábitat, centrada en la interacción entre la sociedad y la naturaleza, es compartida desde varias disciplinas bajo los conceptos de lugar de habitación (Yory, 1998), espacio geográfico (Santos, 1996), territorio de lo urbano (Delgado, 1999) y nido en movimiento (Bachelard, 1993).

Desde la filosofía, Carlos Mario Yory, apoyado en Heidegger (1993), reconoce el "lugar de habitación" como el producto de la interacción del ser del hombre con el estar del mundo, donde el ser y el estar se conjugan en el lugar de habitación (Yory, 1998). Desde la geografía Milton Santos define el "espacio geográfico" como el resultado de la interacción entre los objetos geográficos, que son la forma del hábitat, y el contenido de la sociedad que corresponde a su ser; afirma que las formas son contenido, donde el ser se metamorfosea en existencia (Santos, 1996). Por su parte, el antropólogo Manuel Delgado también reconoce en su concepto de "territorio" asociado a lo urbano la relación entre la composición espacial de este territorio con el estilo de vida que en él acontece, y afirma que toda sociedad es de lugares, así como todo espacio es estructurado en un espacio social (Delgado, 1999). Finalmente, desde la mirada epistemológica y poética de Gastón Bachelard se plantea una asociación entre el espacio y la vida al hablarse del nido como un resultado parcial y nunca acabado del empuje del pecho del ave que lo habita; a través de esta metáfora se revela cómo el movimiento y la vida que ocurre en el interior del nido define tanto su espacio como su forma (Bachelard, 1993).

Siguiendo estas propuestas se encuentran coincidencias en función de un concepto de hábitat referido a proceso, relación e interacción, donde la sociedad y la naturaleza se encuentran en un diálogo recíproco, en el cual este hábitat es producido tanto por la vida que ocurre al interior de la naturaleza como por los límites que esta le establece a la vida que ocurre en su interior.

Este proceso de doble vía está, además, fuertemente condicionado por un componente cultural, manifestado en la estructura de valores que define la relación de los sujetos con su entorno social y ambiental. Por esto, el efecto que tiene la cultura en la relación entre sociedad y naturaleza condiciona el hábitat en función de su contexto histórico y geográfico, y es la razón por la cual este puede ser tan diverso y múltiple como lo sean las culturas de sus habitantes.

Entendemos entonces el concepto de hábitat como el proceso, mediado por la cultura, que ocurre en la relación entre las estructuras socioeconómicas de una población y el espacio físico-ambiental que esta población ocupa en el desarrollo de sus actividades y su vida.

En esta relación, la sociedad constituida por estructuras políticas y socioeconómicas genera demandas hacia las estructuras físico-espaciales 


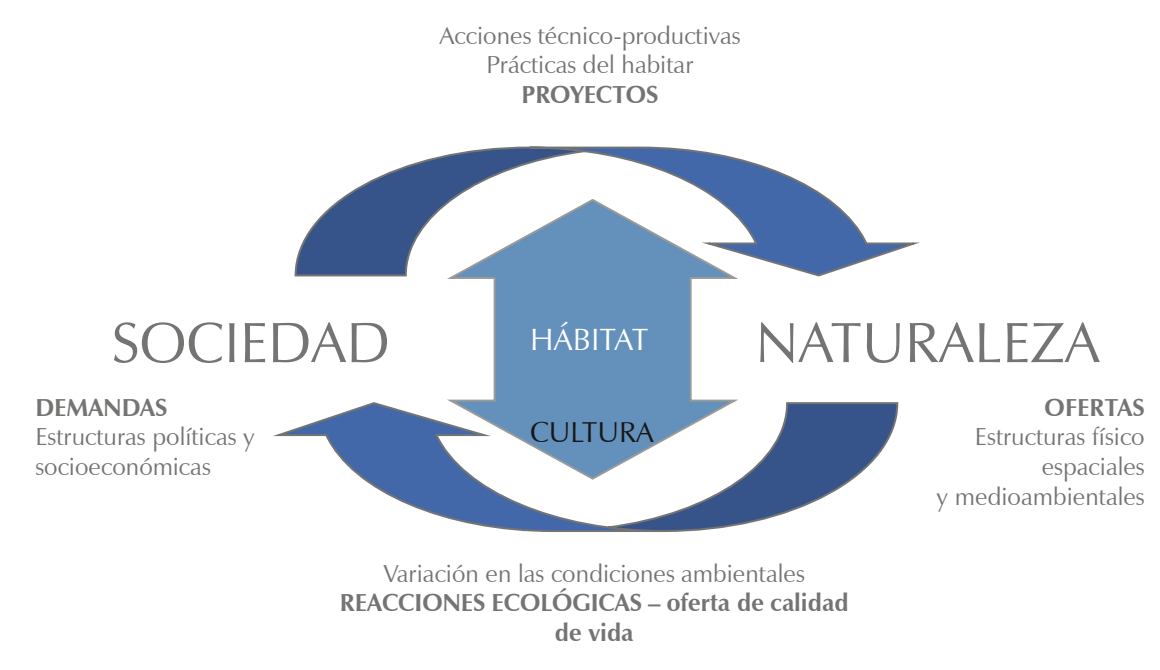

(A) Figura 1. Concepto de hábitat

Fuente: elaboración propia, 2017. CC BY-SA. y medioambientales de la naturaleza. Demandas que se materializan a través acciones técnico-productivas que son en sí mismas prácticas del habitar, las cuales se manifiestan en proyectos de construcción y transformación. A su vez, estas acciones, al transformar la naturaleza, reestructuran las condiciones ambientales y con ello la oferta de calidad de vida que la naturaleza, como soporte de la vida, ofrece a la sociedad (Figura 1).

Desde esta perspectiva de hábitat, las áreas urbanas informales deben ser entendidas más allá de su condición de soporte físico-espacial y ambiental que contiene las actividades de un grupo habitacional con condiciones sociales y económicas en déficit. Implica redimensionar su concepción en función de su permanente transformación y evolución, la cual está dada por la tensión entre el territorio y las personas que lo habitan. Por ello, pensar cualquier acción sobre estas áreas debe considerar la participación de la comunidad, sus necesidades y expectativas, pero también las posibilidades que tienen desde sus recursos, para hacer parte de los procesos de transformación y mejora de sus condiciones urbanas.

Ahora bien, al asumir el hábitat de las áreas urbanas informales como un proceso donde interactúan el territorio y la sociedad, la pregunta sobre la cual interesa avanzar es precisamente ¿qué tipo de proceso es deseable que ocurra en el hábitat de estas áreas?, ¿hacia dónde debe dirigirse?, ¿qué objetivos debe perseguir? En un escenario de crisis ambiental y social como el que vivimos en nuestras ciudades latinoamericanas, donde el crecimiento económico subordina las estructuras ambientales y la segregación socio-espacial, y la inequidad está a la orden del día, nos apoyamos en el concepto de desarrollo sustentable para orientar y definir el tipo de proceso que, desde nuestra perspectiva, debe configurarse en el hábitat de las áreas urbanas informales mediante los procesos de redensificación.

Al revisar la manera como el desarrollo sustentable se incorpora conceptualmente a las reflexiones en torno al desarrollo urbano se reconocen varias interpretaciones, dentro de las cuales Jonathan Barton se refiere a dos que en contraste referencian de manera clara la perspectiva sobre la cual se soporta la investigación. Por un lado, está la perspectiva de desarrollo centrada en el crecimiento urbano como objetivo de corto plazo donde "el crecimiento es comprendido en términos económicos, medido por el PIB en particular, más un conjunto de otras variables asociadas como el empleo, valores del suelo e inversiones" (2006, p. 29).

Y, por otro lado, una perspectiva que busca ser más equilibrada y transversal pues vincula a la noción de desarrollo la consolidación de distintos tipos de capital: financiero, natural, humano, ético y moral, y cultural, sobre los cuales construye el principio de equidad en la sustentabilidad (Barton, 2006). Esta perspectiva, que se ha ido fortaleciendo con el paso de los años, tuvo un hito histórico en 1987 con el informe Brutland y, a partir de allí, en diferentes conferencias y asambleas internacionales se han evidenciado las debilidades del modelo de desarrollo centrado en el crecimiento económico per se, configurándose poco a poco una perspectiva donde el centro es el hombre y la satisfacción de sus necesidades de manera integral, en una relación armónica con la naturaleza y la sociedad.

En este escenario surge y se consolida el concepto de desarrollo sustentable, que incorpora las preocupaciones derivadas de las diferentes conferencias de Naciones Unidas sobre asentamientos humanos, a través de las cuales se estructura la articulación de las dimensiones ambiental, social y económica del desarrollo (Villamizar y Niño, 2009). Así, la Conferencia de las Naciones Unidas sobre el Medio Ambiente Humano (Estocolmo, 1972) se enfoca en guiar las acciones de preservación y desarrollo del ambiente humano, en función del bienestar y el desarrollo económico de la población. La Cumbre de la Tierra, Río de Janeiro 1992, incorpora temas como pobreza, producción y consumo, y protección y manejo de recursos naturales como temas del desarrollo sostenible, planteando además la implementación de la Agenda 21. Por su parte, la Cumbre Río + 5 (Nueva York, 1997), y la Cumbre de la Tierra, Río+10 (Johanesburgo, 2002), evidencian las limitaciones frente a los compromisos asumidos en las cumbres anteriores, y reconocen la urgencia de fortalecer los esfuerzos hacia el desarrollo sustentable a partir del fortalecimiento de sus tres pilares: el desarrollo económico, el desarrollo social y la conservación ambiental.

Sus propuestas se recogen posteriormente en la Declaración de los Objetivos del Milenio (ODM) y la formulación de los Objetivos de Desarrollo Sostenible (ODS) de la agenda 2030, y se trasladan a la problemática específica de los asentamientos humanos mediante la adopción de la Nueva Agenda Urbana. Esta última, redactada en 2016 en el marco de la Tercera Conferencia de las Naciones Unidas sobre Vivienda y DesarroIlo Urbano Sostenible, Habitat III, plantea una 
Castiblanco-Prieto, J. J., Aguilera-Martínez, F. A., \& Sarmiento-Valdés, F. A. (2019). Principios, criterios y propósitos de desarrollo sustentable para la redensificación en contextos urbanos informales. Revista de Arquitectura (Bogotá) 2I(I), 2I-33. doi: http://dx.doi.org/I0.147।8/ RevArq.2019.21.1.1209

propuesta estratégica que pretende orientar la definición de políticas, programas y proyectos fundamentados en el desarrollo urbano sostenible (Naciones Unidas, 2017).

Desde este marco se asume que el hábitat sustentable en las áreas urbanas informales es ante todo un proceso, el cual debe orientarse hacia la transformación continua de sus condiciones deficitarias mediante su mejora integral y el incremento de la calidad de vida de sus habitantes. Desde esta perspectiva, el proceso de desarrollo sustentable en el hábitat se asocia a una idea de dignidad humana que se enfoca en la satisfacción de necesidades y expectativas de las personas, así como en el ejercicio de los derechos ciudadanos proyectados en la ciudad y el hábitat que esta representa (Figura 2).

De esta manera, la redensificación como alternativa de desarrollo sustentable para la transformación de las áreas urbanas informales debe garantizar la mejora integral de sus condiciones urbanas y la afectación positiva en la calidad de vida para sus habitantes.

\section{Principios, criterios y propósitos para la intervención en áreas urbanas informales}

El enfoque de desarrollo sustentable presentado anteriormente es el marco orientador para la definición de lineamientos y la formulación de recomendaciones estratégicas que se proponen para la planeación y el diseño en proyectos de redensificación para las áreas urbanas informales. Esta propuesta se apoya en la revisión comparada de la estructura de categorías y la definición de variables que utilizan tres sistemas de indicadores para la evaluación del desarrollo urbano sustentable.

La primera, los indicadores de la Iniciativa ciudades emergentes y sostenibles del Banco Interamericano de Desarrollo (BID, 2013), los cuales se soportan en tres dimensiones de la sostenibilidad urbana: la ambiental y de cambio climático, la urbana, y la fiscal y de gobernabilidad. Para cada una de estas dimensiones la iniciativa planea una serie de pilares generales, con sus temas y subtemas, definiendo una estructura ordenada y relacionada en función de los aspectos que considera estratégicos para alcanzar la sostenibilidad urbana. La segunda, la propuesta de indicadores de calidad de vida urbana para la ciudad de Quilmes en Argentina (Leva, 2005), que se estructura a través de aspectos de hábitat y socioeconómicos, los cuales establecen unas áreas temáticas que inciden particularmente en las condiciones de sostenibilidad desde la perspectiva de la satisfacción del conjunto de necesidades que se relacionan con la existencia y el bienestar de los ciudadanos. Y, finalmente, el sistema de indicadores de la propuesta de política ambiental local para la ciudad de Manizales, conocida como BioManizales (Marulanda, 2000), que desde los componentes ambiental,

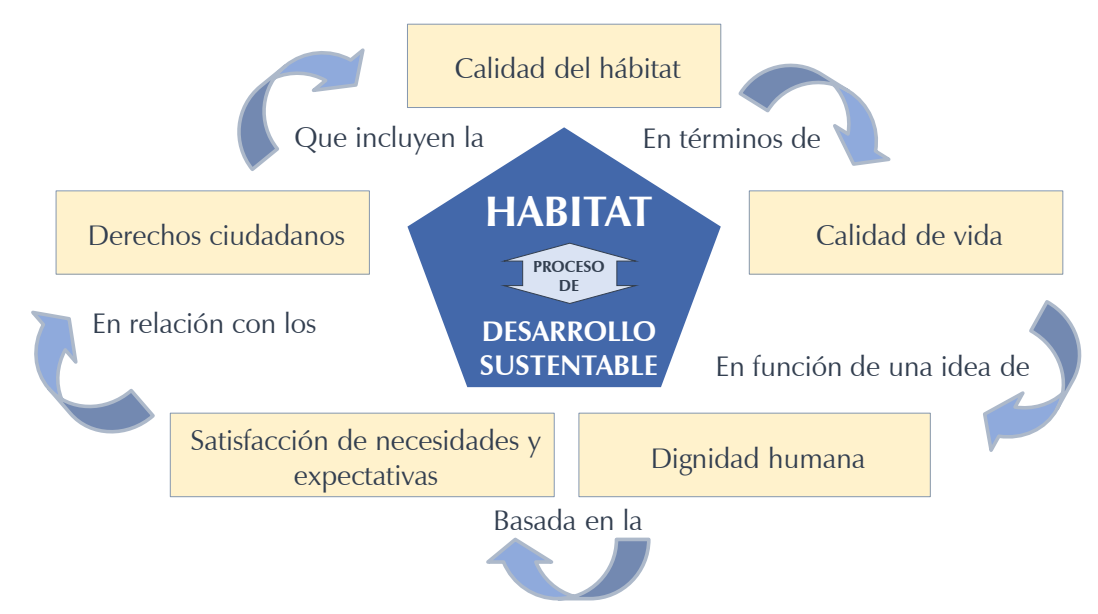

social y económico define factores y variables que guían el desarrollo sostenible de la ciudad.

La revisión comparada permitió identificar temas comunes en la orientación general de la sostenibilidad urbana y sirvió como referente para la consolidación de nuestra propuesta en tres niveles: principios, criterios y propósitos de desarrollo sustentable en el hábitat urbano informal. En esta propuesta, estos corresponden a un sistema de categorías que parten de las dimensiones tradicionales del desarrollo sustentable -económica, social y ambiental-, y van configurando la articulación de condiciones estratégicas que deberán ser alcanzadas, las cuales definen un deber ser del desarrollo sustentable aplicado al hábitat informal.

Este sistema, a partir de su carácter general, busca la integralidad en la lectura y el tratamiento de las áreas urbanas informales, reconociendo las interrelaciones y articulaciones que existen entre sus dimensiones, desde los niveles más conceptuales del deber ser, donde se definen los principios y criterios, hasta unos de carácter más operativo, donde se establece para cada criterio un binomio de propósitos que le apuntan a la aplicación concreta de programas y proyectos.

La descripción del modelo propuesto parte de un primer nivel donde se ubican las dimensiones abstractas del desarrollo sustentable (ambiental, social y económica), y desde allí, con base en los análisis comparativos mencionados, se plantean los principios de habitabilidad, equidad y eficiencia como conceptos intermedios que, individualmente, buscan la articulación de dos de las dimensiones generales ubicadas en el nivel inmediatamente inferior. Así, la habitabilidad es un principio de desarrollo sustentable que atiende de manera simultánea a su dimensión social y ambiental, pues hace referencia al equilibrio y bienestar que se alcanza frente al entorno tanto social como físico-espacial del territorio (Espinoza y Gómez, 2010). Por su parte, el principio de equidad atiende a las dimensiones social y económica pues garantiza el acceso democrático e igualitario, para todos los integrantes de la sociedad, a las condiciones de calidad de vida, los servicios, las oportunidades y los recursos propios del sistema económico de la ciudad (Lezama y Domínguez, 2006). Por último, el principio de la eficiencia, que responde a su vez a las dimensiones económica y ambiental del hábitat, garantiza
(A) Figura 2. Perspectiva de desarrollo sustentable en el hábitat de las áreas urbanas informales

Fuente: elaboración propia, 2017. CC BY-SA. 


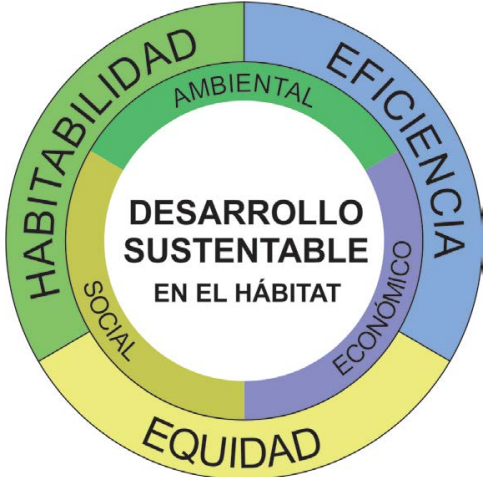

A Figura 3. Dimensiones y principios del desarrollo sustentable en el hábitat

Fuente: elaboración propia, 2018. CC BY-SA.

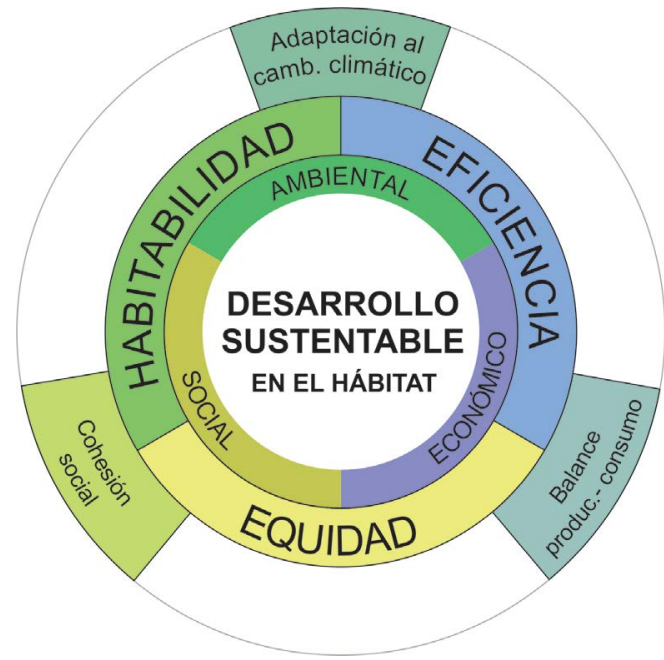

(A) Figura 4. Criterios para el desarrollo sustentable derivados de la articulación de los principios de habitabilidad, eficiencia y equidad Fuente: elaboración propia, 2018. CC BY-SA

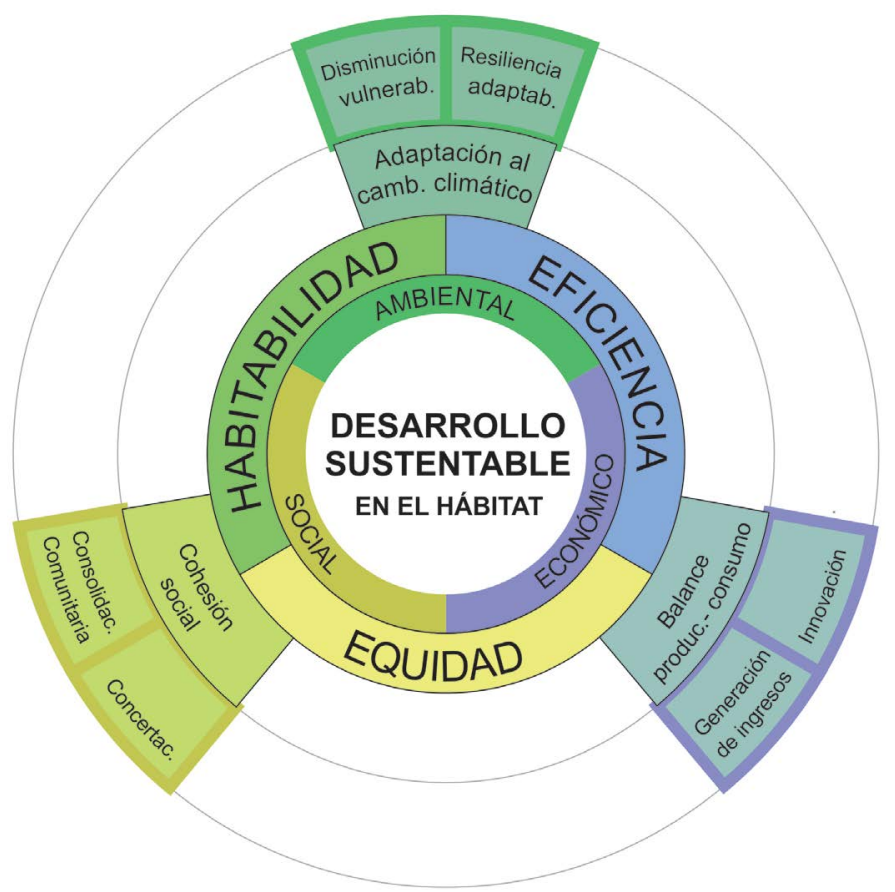

A Figura 5. Propósitos para el desarrollo sustentable derivados de los criterios que articulan los principios de habitabilidad, eficiencia y equidad

Fuente: elaboración propia, 2018. CC BY-SA. que los procesos y flujos de energía, materiales y recursos financieros que provee el proceso de interacción con el ambiente (natural y antrópico) sean utilizados de manera equilibrada con la naturaleza y con las demandas de la sociedad (Figura 3).

En el siguiente nivel, derivados de los principios, se encuentran los criterios de desarrollo sustentable, con los cuales se definen las temáticas específicas que configuran el escenario ideal perseguido desde la perspectiva planteada. Nuevamente, haciendo énfasis en las interrelaciones entre los componentes de nuestro sistema, los criterios de adaptación al cambio climático, cohesión social y balance entre producción y consumo surgen de la interrelación entre tres de los principios del sistema que se encuentran en el nivel anterior del modelo: habitabilidad, eficiencia y equidad (Figura 4)

De esta manera, el criterio de adaptación al cambio climático es el de carácter más ambiental tanto para el principio de habitabilidad como para el de eficiencia. Por el lado de la habitabilidad, en función de la disminución de los riesgos y las vulnerabilidades en el contexto del cambio climático; y por el lado de la eficiencia, en función de la generación de procesos eficientes para asegurar la adaptabilidad y resiliencia frente a este fenómeno.

Asimismo, los criterios de cohesión social y balance entre producción y consumo articulan los principios de habitabilidad y equidad en el primer caso, y de equidad y eficiencia en el segundo. La cohesión social, planteada como el objetivo de carácter más social para los principios de habitabilidad y equidad, pone énfasis en la consolidación de la comunidad para asegurar un tejido social que garantice bienestar, y en la concertación entre actores diversos que aseguren la inclusión social sin discriminación. Por su parte, el balance entre producción y consumo es el criterio más económico para los principios de eficiencia y equidad pues se orienta hacia garantizar una generación de ingresos suficiente para satisfacer las necesidades de los habitantes, en el marco de un proceso de innovación que asegure eficiencia en su uso.

Lo anterior da cuenta de la lógica tras la definición de cada criterio y propósito, y cómo estos establecen las temáticas generales para la delimitación de objetivos específicos desde la perspectiva del desarrollo sustentable (Figura 5).

El sistema se completa mediante otros seis criterios, que corresponden a las dos dimensiones que articula cada principio (Figura 6). Para el principio de la habitabilidad, desde su dimensión ambiental, el criterio de bienestar físico que asegura la seguridad y el confort; y desde su dimensión social, el criterio de bienestar social que persigue la formación de sentidos de apropiación y pertenencia, y el acceso universal a servicios urbanos. Para el principio de la equidad, desde su dimensión social, el criterio de gobernabilidad que se 
consigue mediante la participación multiactoral en la toma de decisiones y el empoderamiento de la sociedad como base para la participación política y la gestión; y desde su dimensión económica, el criterio de asequibilidad a los bienes, servicios y beneficios integrales del hábitat, que se obtiene mediante estructuras de solidaridad y cooperación, y los procesos de progresividad que aseguran su obtención. Finalmente, para el principio de eficiencia, en su dimensión económica, el criterio de integración funcional desde la lógica de la competitividad y la conectividad; y la para su dimensión ambiental, el criterio del metabolismo urbano a partir del uso racional de los materiales y la energía.

El sistema completo, como propuesta de principios, criterios y propósitos de desarrollo sustentable en el hábitat de las áreas urbanas informales, como fue presentado, apunta a configurar el escenario para el hábitat de las áreas urbanas informales mediante la interacción e interrelación de 3 dimensiones, 3 principios, 9 criterios y 18 propósitos (Figura 7), los cuales son la base para la formulación de los requerimientos estratégicos de diseño que se presentan en el siguiente apartado.

\section{Requerimientos estratégicos de desarrollo sustentable para el diseño arquitectónico en áreas urbanas informales mediante proyectos de redensificación}

A partir de las precisiones realizadas en torno a la condición procesal y relacional del hábitat en las áreas urbanas informales, donde la participación de la población juega un papel relevante en la configuración y uso, se formulan una serie de lineamientos de diseño para los proyectos de redensificación con los cuales se impulsa su potencialidad, en función de la reestructuración y mejora integral de estas áreas. La formulación de estos lineamientos se articula al sistema de principios, criterios y propósitos de desarrollo sustentable planteado anteriormente, y con ello busca garantizar una mejora plena y sostenida en el tiempo de las condiciones de vida de las personas que habitan en estos territorios.

Los requerimientos estratégicos que se proponen son de carácter práctico y sistémico pues tienen la finalidad de apoyar la toma de decisiones en la definición de los proyectos de mejoramiento, bajo la modalidad de redensificación, de forma articulada y en relación con los objetivos del desarrollo sustentable. Están planteados como un pliego de lineamientos que se estructura en cuatro categorías, de acuerdo con su carácter técnico, programático, espacial o socioeconómico.

Los requerimientos técnicos hacen referencia a los asuntos constructivos y de la materialidad del proyecto, a temas de infraestructura, redes y sistemas técnicos, bioclimática y ergonomía que son necesarios para garantizar unas condiciones adecuadas de habitabilidad, median-

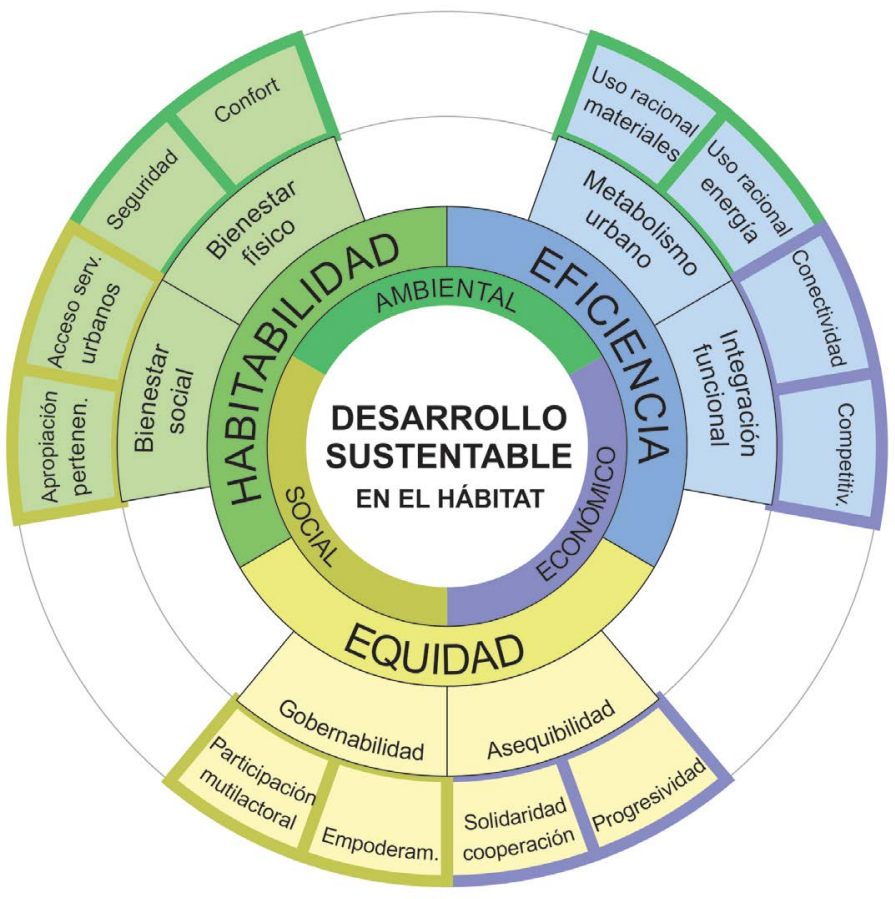

(A) Figura 6. Criterios y propósitos para el desarrollo sustentable que completan el sistema

Fuente: elaboración propia, 2018. CC BY-SA.

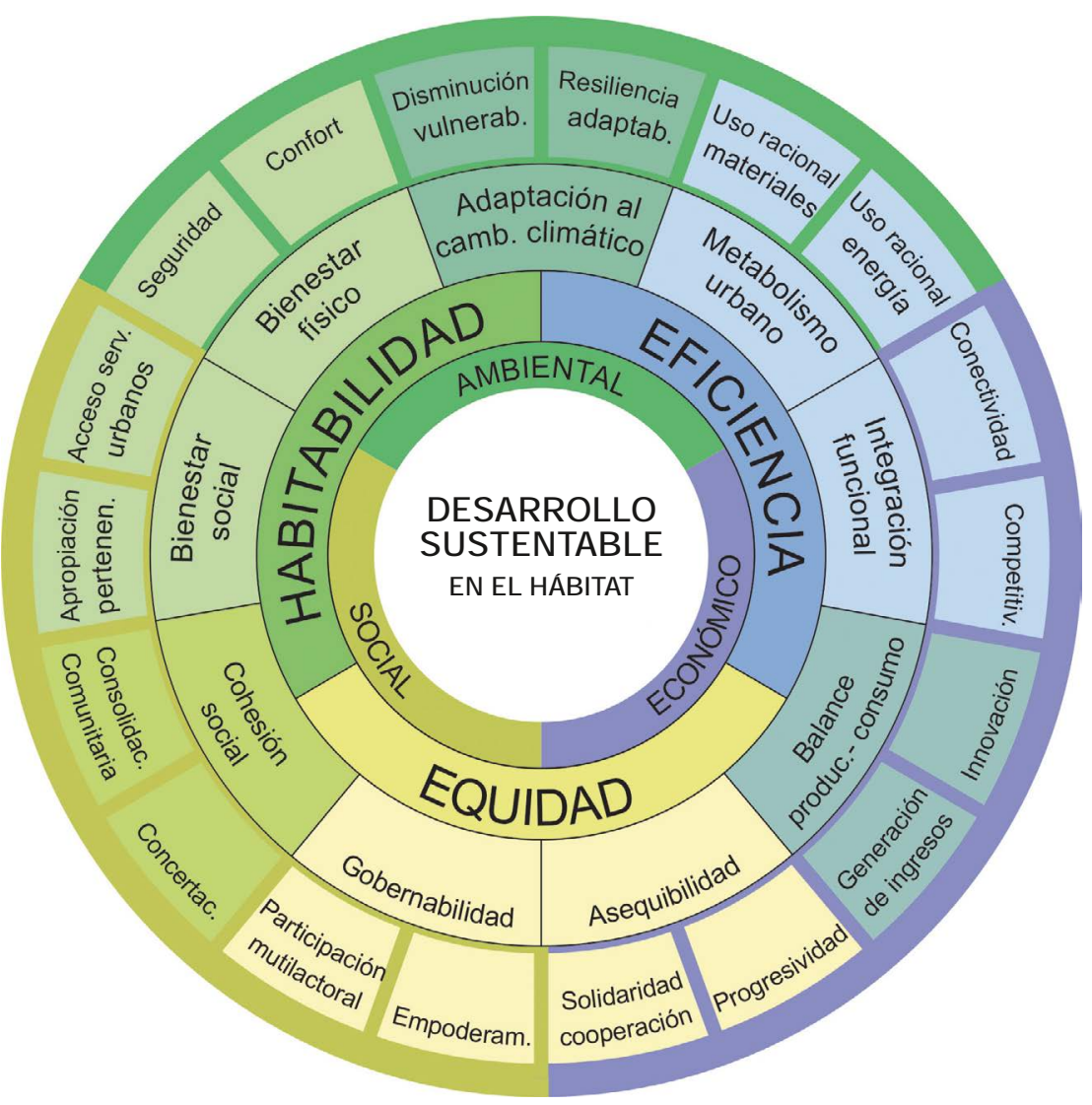

(A) Figura 7. Propuesta de principios, criterios y propósitos para el desarrollo sustentable del hábitat en áreas urbanas informales

Fuente: elaboración propia, 2018. CC BY-SA.

te un uso eficiente de recursos y procurando un bienestar social para los habitantes involucrados con el proyecto de reasentamiento. Los requerimientos programáticos se refieren a las actividades y los usos que se deben propiciar en el proyecto mediante la oferta específica de algunos espacios, de manera que se logren los propósitos de desarrollo sustentable en relación con la generación de ingresos, el bienestar, la cohesión social y el fortalecimiento de las redes sociales que 
sostienen el territorio. Los de tipo espacial garantizan las relaciones entre el espacio público y el privado, así como las relaciones con el entorno y contexto de manera que se creen y consoliden las articulaciones necesarias para la incorporación en circuitos productivos y corredores de servicios urbanos. Por último, los requerimientos socioeconómicos que tienen su énfasis en las personas y la comunidad, en su participación en las diferentes etapas del proyecto, su formación, sus actividades productivas y culturales, y, sobre todo, en aquellos aspectos que garantizan oferta social y comunitaria que es complementaria a la infraestructura física del proyecto.

En la Tabla 1 se listan los requerimientos estratégicos planteados y se señalan las coincidencias que tienen con el sistema de principios, criterios y propósitos, por los aportes que uno a uno hace para alcanzar los diferentes propósitos de desarrollo sustentable. Se evidencia cómo algunos de estos requerimientos tienen efectos en más de un propósito, y adquieren una relevancia singular por la capacidad de impactar en el sistema general de propósitos.

En la propuesta se plantean 55 requerimientos estratégicos en total. De estos, los 18 de carácter técnico (Tabla 1, id 1 a 18) están principalmente orientados a suplir los objetivos del principio de habitabilidad. Se destacan por responder a un número significativo de propósitos de desarrollo sustentable, aquellos que buscan garantizar la accesibilidad universal; la durabilidad, estabilidad, eficiencia e innovación en los sistemas constructivos; y las condiciones adecuadas de confort. También son relevantes los que abordan temas de cuidado del medio ambiente y la disminución de la huella ecológica de los proyectos mediante el empleo de mano de obra local y fomento de energías alternativas.

Por su parte, aunque los lineamientos de tipo programático son solo seis (Tabla 1, id 19 a 24), estos tienen un fuerte impacto en el sistema pues articulan las necesidades de los habitantes con la oferta de actividades que el proyecto de redensificación acoge en su infraestructura; por esta razón todos los requerimientos de carácter programático están articulados y tienen gran capacidad de aportar al alcance de los propósitos de desarrollos sustentable.

Por otro lado están los nueve requerimientos de carácter espacial (Tabla 1, id 25 a 33), que se centran en la definición de las relaciones físicas y materiales de tipo arquitectónico consideradas en el proyecto de redensificación. Los más relevantes, en relación con los propósitos de desarrollo sustentable, son los que garantizan una adecuada relación entre el espacio público y los equipamientos, en términos de accesibilidad, permeabilidad e inclusividad, y aquellos que propenden por la vida urbana y la seguridad, desde la lógica de la mixtura de usos, la flexibilidad y adaptabilidad del espacio público.
Por último, los 22 requerimientos de carácter socioeconómico (Tabla 1, id 24 a 55), que son los más numerosos, y aunque no presentan una oferta tan amplia en las relaciones con los propósitos vinculados al principio de habitabilidad, son fundamentales en su articulación con los de equidad y eficiencia, y consolidan la integralidad que se desea para el modelo. Son estos requerimientos los que aterrizan la mirada procesal de hábitat, donde la sociedad, junto con sus necesidades y deseos, son parte indisoluble del territorio, pues de su estabilidad y buen funcionamiento dependen la sostenibilidad en el tiempo de los procesos y los niveles de calidad de vida en el territorio.

En este sentido, los requerimientos socioeconómicos que se destacan en el proceso de redensificación están asociados al libre acceso a la información para los habitantes, tanto en las etapas de su estructuración como en su posterior uso. Igualmente, son relevantes los requerimientos asociados al fortalecimiento de las redes sociales en la comunidad, bien sea a partir de la construcción de una visión y un horizonte común, o mediante el fomento de proyectos colectivos sobre la base de la participación de la comunidad empoderada, que asume responsabilidades concretas para cada uno de sus integrantes.

\section{Discusión}

Como se evidencia en los resultados de este trabajo, centrarse en las personas, en las comunidades, en los pobladores de la ciudad informal a fin de pensar y actuar sobre sus territorios resulta fundamental para asegurar la sustentabilidad, tanto de su componente físico como del social. Coincidimos con los planteamientos que reconocen el papel de la comunidad en los procesos de transformación, mejoramiento y consolidación de las áreas de origen informal (Garzón, AbeIla y Brañes, 2005); que valoran su experiencia, capacidades y espíritu de sobrevivencia (Carvajalino, 2005), y que reconocen la necesidad de integrarlos a los procesos productivos y la oferta de bienes y servicios de la ciudad formal, en un tejido urbano soportado en el desarrollo sustentable como patrón de desarrollo (Calvo, 2000).

Si bien otros autores ya han propuesto algunos modelos para hacer operativo el concepto del desarrollo sustentable y aplicarlo a la evaluación, planeación y formulación de proyectos urbanos y arquitectónicos (Regolini, 2008; López, 2004; López y López, 2012), nuestra propuesta, desde la perspectiva procesal y relacional del hábitat sobre la cual trabajamos, pone su énfasis en las interrelaciones para formular aplicaciones concretas al diseño de proyectos de redensificación. Vincula las diferentes categorías de desarrollo sustentable, que reconocen su condición compleja e integral, y las aterriza al proyecto mediante lineamientos estratégicos de diseño que aportan en la definición 
Castiblanco-Prieto, J. J., Aguilera-Martínez, F. A., \& Sarmiento-Valdés, F. A. (2019). Principios, criterios y propósitos de desarrollo sustentable para la re-densificación en contextos urbanos informales. Revista de Arquitectura (Bogotá) 2/(I), 2I-33. doi: http://dx.doi.org//0.|47/8/ RevArq.2019.21.1.1209

PRINCIPIOS

$\rightarrow$ Tabla 1. Requerimientos estratégicos

planteados para cada uno de los propósitos de

desarrollo sustentable en el hábitat

SCRITERIOS

Fuente: elaboración propia, 2018. CC BY-SA.

PROPÓSITOS

\begin{tabular}{|c|c|c|c|}
\hline Id & $\begin{array}{c}\text { Tipo de } \\
\text { lineamiento }\end{array}$ & Requerimientos estratégicos de desarrollo sustentable para el diseño arquitectónico \\
\hline &
\end{tabular}

1 Técnico Accesibilidad universal en viviendas, espacio público y equipamientos

2 Técnico Condiciones de iluminación noctura adecuadas en el espacio público (vida urbana y seguridad)

\begin{tabular}{|c|l|l}
3 & Técnico & Estabilización de rondas de cuerpos hídricos
\end{tabular}

4 Técnico Estabilización de taludes y pendientes

5 Técnico $\begin{aligned} & \text { Fomento de uso del espacio público en horas de la noche garantizando condiciones adecuada } \\ & \text { iluminación }\end{aligned}$

luminación

$6 \quad$ Técnico $\begin{aligned} & \text { Infraestructura para la gestión eficiente de residuos } \\ & \text { (separación en la fuente, compostaje, reciclaje, as }\end{aligned}$

(separación en la fuentè, compostaje, reciclaje, aseo en el espacio público)

7 Técnico $\begin{aligned} & \text { Innovacion en los sistemas constructivos } \\ & \text { (construcción seca, de piezas ensamblables y reutilizables en espacios progresivos-por etapas) }\end{aligned}$

8 Técnico Manejo de materiales y sistemas constructivos estables, duraderos $y$ seguros

9 Técnico Manejo de criterios bioclimáticos para garantizar confort térmico, acústico, lumínico, olfativo

10 Técnico Manejo de criterios ergonómicos en el diseño de los espacios públicos y privados

11 Técnico Manejo de sistemas de drenaje urbano sustentable: infiltración de la lluvia al suelo

12 Técnico Manejo de sistemas que faciliten limpieza, mantenimiento e inspección en redes

13 Técnico Orientación adecuada y sistema de cerramiento que garantice iluminación y ventilación natural

14 Técnico $\begin{aligned} & \text { Renaturalización del espacio mediante siembra de especies nativas } \\ & \text { y ampliación de la capa vegetal }\end{aligned}$

15 Técnico Sistemas de almacenamiento y reserva de agua

16 Técnico Sistemas de aprovechamiento de aguas lluvias y aguas grises. Filtración y reutilización

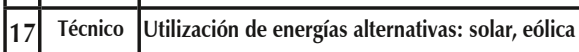

18 Técnico Utilización de materiales locales

19 Programa Aprovechamiento productivo del suelo y el agua mediante agricultura urbana

20 Programa $\begin{aligned} & \text { Espacio público caracterizádo para usuarios específicos } \\ & \text { (perspectiva de edad } y / 0 \text { género) }\end{aligned}$

21 Programa Espacios para actividades culturales, educativas, recreativas, deportivas y/o de bienestar social

(equipamientos urbanos) spacios para actividades productivas en el espacio comunal y la vivienda
talleres, comercios, oficinas, insumos para progresividad, agricultura urbana)

23 Programa Espacios para formación, educación, emprendimiento (capacitaciones, autogestión)

24 Programa $\begin{aligned} & \text { Oferta pertinente de bienes, servicios y espacios requeridos por el proyecto } \\ & \text { y el contexto urbano (ans }\end{aligned}$

24 y el contexto urbano (espacio público, equipamientos, comercio, paisaje)

25 Espacial Aprovechamiento y creación de visuales y paisaje

26 Espacial $\begin{aligned} & \text { Articulación espacio público-equipamiento estimulando encuentro entre vecinos } \\ & \text { (accesibilidad, permeabilidad, inclusividad) }\end{aligned}$

27 Espacial Articulación al sistema de movilidad urbana

28 Espacial $\begin{aligned} & \text { Espacios con posibilidad de intervención por la comunidad } \\ & \text { (reforestación en áreas verdes, mejoramiento de infraestruc }\end{aligned}$

29 Espaid

29 Espacial $\begin{aligned} & \text { Espacios con posibilidad de subdivisión e independencia } \\ & \text { en la vivienda y el equipamiento (arriendo) }\end{aligned}$

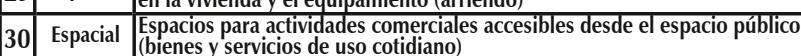

$31 \quad$ Espacial $\begin{aligned} & \text { Espacios públicos y privados adaptables y flexibiles } \\ & \text { (permiten cambios según necesidades y por etapas) }\end{aligned}$

32 Espacial Usos mixtos articulados por el espacio público (garantizando vida urbana y seguridad)

33 Espacial Vivienda mínima con posibilidad de ampliación para disminuir el costo inicial

34 Socio-eco- Acceso libre y pertinente a información útil para el fortalecimiento

nómico del proyecto en todos sus componentes (internet, bases de datos, etc.)

$\begin{gathered}\text { Socio-eco- } \\ \text { nómico }\end{gathered}$
Acciones colectivas de embellecimiento y ornato en el espacio público

Socio-eco-
nómico Acompañamiento, formación y apoyo a los liderazgos locales

37 Socio-eco- Articulación con programas y proyectos externos en temas de mejoramiento barrial

nómico (Cámara de Comercio, Jardín Botánico, Ipes)

$38 \begin{gathered}\text { Socio-eco- } \\ \text { nómico }\end{gathered}$ Aumento y diversificación de fuentes de financiación

39 Socio-eco- Construcción colectiva de la imagen y el paisaje cultural del barrio

40 Socio-eco- Construcción de una visión futura común sobre el proyecto de redensificación que aglutine los

nómico intereses de los diferentes actores y defina un horizonte de trabajo

41 Socio-eco- $\begin{gathered}\text { Fomento de proyectos comunes entre usuarios y con vecino } \\ \text { nómico }\end{gathered}$

41 nómico (de apropiación del espacio, culturales, educativos, productivos, de emprendimiento, etc.)

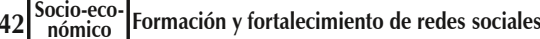

Socio-eco-

$\begin{gathered}\text { Socio-eco- } \\ \text { nómico }\end{gathered}$
Fortalecimiento del control social y político sobre las acciones e iniciativas de carácter colectivo

$44 \begin{gathered}\begin{array}{c}\text { Socio-eco- } \\ \text { nómico }\end{array} \\ \begin{array}{l}\text { Incorporación y fortalecimiento de colectivos sociales, organizaciones comunitarias } \\ \text { y agrupaciones de personas con temas específicos de vulnerabilidad o discapacidad }\end{array}\end{gathered}$

$45 \begin{gathered}\text { Socio-eco- } \\ \text { nómico }\end{gathered}$ Incremento del corporativismo, cooperativismo y la asociación entre usuarios y vecinos

46 Socio-eco- $\begin{gathered}\text { Incremento y diversificación de las actividades productivas y del emprendimiento } \\ \text { nómico }\end{gathered}$

Socio-eco-- Oferta de actividades en todos los horarios (24/7) asociadas al espacio público
nómico

nocio-eco- Participación activa de la comunidad con responsabilidades concretas, en las diferentes

8 nómico fases del proyecto (formulación, diseño, gestión, construcción y uso)

9 Socio-eco- Oferta de educación y capacitación técnica en con miras al fortalecimiento

Socio-eco-
nómico $\begin{aligned} & \text { Pedagogía social y capacitación a usuarios para la gestión eficiente de recursos } \\ & \text { (agua, enenergía, residuos, la progresividad de la vivienda, dinero, etc.) }\end{aligned}$

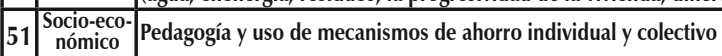

Socio-eco- Presencia de actores diversos en la formulación y gestión de accioness sobre el proyecto

52 Socio-eco- $\begin{gathered}\text { (universidades, empresa privada, administración pública, organizaciones sociales, } \\ \text { nómico }\end{gathered}$

nomico agencias de cooperación)

Socio-eco-Presencia de canales de comunicación eficaces y colectivo

nómico para la difución e impulso de iniciativas comunales

$54 \begin{gathered}\text { Socio-eco- } \\ \text { nómico }\end{gathered}$ Presencia local de entidades financieras o crediticias (tradicionales o cooperativas)

Socio-eco-
nómico Utilización de mano de obra local

5 nómico

Cantidad de requerimientos estratégicos para cada propósito de desarrollo sustentable

\begin{tabular}{|c|c|c|c|c|c|c|c|c|c|c|c|c|c|c|c|c|}
\hline \multicolumn{3}{|c|}{ EFICIENCIA } & & & & & & & & & & & & & \multicolumn{2}{|c|}{ EFICIENCIA } \\
\hline & & & \multicolumn{7}{|c|}{ EQUIDAD } & & & & & & & \\
\hline & & & & & & & & & \multicolumn{8}{|c|}{ HABITABILIDAD } \\
\hline $\begin{array}{c}\text { Metabolis- } \\
\text { mo } \\
\text { urbano }\end{array}$ & \multicolumn{2}{|c|}{$\begin{array}{c}\text { Integración } \\
\text { funcional }\end{array}$} & \multicolumn{2}{|c|}{\begin{tabular}{|c|}
$\begin{array}{c}\text { Balance } \\
\text { entre } \\
\text { producción } \\
\text { y consumo }\end{array}$ \\
\end{tabular}} & \multicolumn{2}{|c|}{$\begin{array}{l}\text { Asequi- } \\
\text { bilidad }\end{array}$} & \multicolumn{2}{|c|}{$\begin{array}{c}\text { Gobernabi- } \\
\text { lidad }\end{array}$} & \multicolumn{2}{|c|}{$\begin{array}{l}\text { Cohesión } \\
\text { social }\end{array}$} & \multicolumn{2}{|c|}{$\begin{array}{l}\text { Bienestar } \\
\text { social }\end{array}$} & \multicolumn{2}{|c|}{$\begin{array}{l}\text { Bienestar } \\
\text { físico }\end{array}$} & \multicolumn{2}{|c|}{$\begin{array}{l}\text { Adaptación } \\
\text { al cambio } \\
\text { climático }\end{array}$} \\
\hline 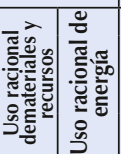 & 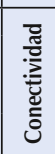 & 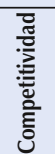 & 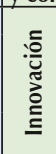 & 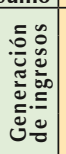 & 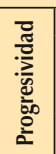 & 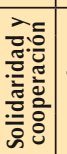 & 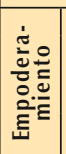 & 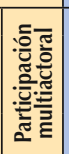 & 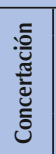 & 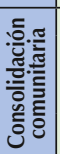 & 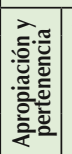 & 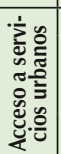 & 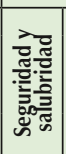 & نे & 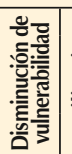 & 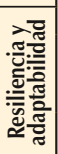 \\
\hline
\end{tabular}


del programa, el espacio, la técnica y su articulación con el desarrollo social de los pobladores involucrados con el proyecto.

Si bien la propuesta delinea algunas consideraciones en relación con la participación de actores de diferentes sectores que articulan sus intereses en torno a los procesos de redensificación, como estrategia de gestión para la viabilización de los proyectos de este tipo en áreas informales, este estudio requiere ser modelado y evaluado financieramente para poder validar económicamente sus planteamientos.

A pesar de ello, la propuesta de redensificación como un proyecto de hábitat procesal y relacional, se consolida como un plan de convivencia que se soporta en la construcción y consolidación de redes sociales mediante el fortalecimiento del arraigo y del sentido de pertenencia. De esta manera, este tipo de proyectos pueden ser un escenario para la consolidación de redes sociales solidarias capaces de desarrollar procesos participativos en la planeación, construcción y administración del territorio, a fin de garantizar su sustentabilidad en términos de habitabilidad, equidad y eficiencia del hábitat.

Así, la arquitectura del proyecto de redensificación no hace referencia exclusivamente a la arquitectura de los espacios y la materialidad, sino más bien a una arquitectura de procesos; por tanto, su calidad no está dada solo por sus condiciones físico-espaciales, sino por las posibilidades que ella ofrezca para construir territorio, desarrollar sentidos de apropiación y pertenencia, y, sobre todo, para satisfacer necesidades asociadas a la calidad de vida de sus pobladores.

\section{Conclusiones}

Desde el enfoque de hábitat y desarrollo sustentable que orienta este trabajo se concluyen las siguientes consideraciones en función de posibles procesos de redensificación para las áreas urbanas informales:

- Las dinámicas poblacionales que demandan del territorio un máximo aprovechamiento del suelo en detrimento de la dotación de espacio público y los equipamientos pueden compensarse mediante el aumento de la densidad urbana, siempre y cuando esta conlleve una liberación de área en los primeros pisos que destine suelo para estos dos componentes urbanos.

- La ocupación en áreas de alto riesgo no mitigable, donde hay gran probabilidad de catástrofes, pérdidas económicas y de vidas, requiere de procesos de reasentamiento que tienen en la redensificación del territorio una oportunidad para evitar situaciones de gentrificación.

- La producción colectiva del territorio, en procesos comunitarios para el desarrollo de infraes- tructuras urbanas colectivas configura y fortalece la cohesión social y las capacidades de autogestión de las comunidades. La incorporación de esquemas efectivos de participación en las diferentes etapas de los proyectos de redensificación (formulación, gestión, diseño, construcción y vida útil), puede fortalecer el tejido social de las comunidades.

- La reestructuración del territorio mediante procesos formales de redensificación, construidos técnicamente y dotados con servicios domiciliarios de calidad, puede incidir en la mejora de las condiciones de calidad urbana y de la vivienda siempre y cuando se consolide un modelo de participación entre la empresa privada, la pública, la sociedad organizada y otros posibles actores que viabilicen económicamente la operación.

- Si bien hay ejemplos de procesos de redensificación en diferentes escenarios latinoamericanos, sus niveles de éxito medidos en función de un desarrollo integral por parte de sus habitantes debe revisarse, pues los proyectos urbanos siguen teniendo un sesgo importante sobre la infraestructura, que desatiende las consideraciones que estos proyectos tienen de manera amplia en la calidad de vida de sus habitantes.

- La redensificación de las áreas urbanas informales es una oportunidad para concretar en ellas el discurso de la descentralización, siempre que se desarrolle su potencial para generar escenarios de intensa vitalidad urbana sobre la base de la mixtura de usos, donde convivan equilibradamente los espacios para la formación y la creación, junto con la oferta de bienes, servicios, empleo y emprendimiento.

- Los programas de mejoramiento integral de barrios, en cualquiera de sus modalidades, incluido el reasentamiento, requieren de manera ineludible de la participación de la comunidad, no solo para garantizar la sostenibilidad en el tiempo de los procesos que se den en el territorio a través de la apropiación comunitaria, sino sobre todo para lograr que estos continúen y se consoliden, mediante nuevas acciones gestionadas por una comunidad que se forma y adquiere nuevas capacidades con cada intervención.

- Tras la etapa de aplicación del modelo en el proyecto académico de re-densificación se reconoce que la inclusión de espacios que fomenten tanto las actividades productivas en el espacio comunal y la vivienda como las actividades de formación, educación y emprendimiento, así como la articulación del espacio público y del equipamiento para estimular el encuentro entre vecinos, son los tres requerimientos estratégicos que tienen mayor impacto en la consecución de los propósitos de desarrollo sustentable de nuestro sistema, razón por la cual deben ser tenidos en cuenta de manera singular en los proyectos de re-densificación en áreas urbanas informales. 


\section{Referencias}

Bachelard, G. (1993). La poética del espacio. Bogotá: Fondo de Cultura Económica.

Banco Mundial (s. f.). Datos de libre acceso del Banco Mundial. Recuperado de https:// datos.bancomundial.org/

Barton, J. (2006). Sustentabilidad urbana como planificación estratégica. Revista Eure, 32(96), 27-45. Doi: http://dx.doi.org/10.4067/SO25071612006000200003

Banco Interamericano de Desarrollo (2013). Anexo 2. Indicadores de la Iniciativa Ciudades Emergentes y Sostenibles. Washington: BID. Recuperado de https://www.iadb.org/es/ciudades

Calvo Cerda, P. (2000). Desarrollo y sustentabilidad de asentamientos precarios urbanos. Revista Invi, 15(40), 21-38 Recuperado de http://www.revistainvi.uchile.cl/index.php/ INVI/article/view/260/779

Carvajalino Bayona, H. (2013). Aprendiendo del Barrio la Paz: un escenario desde el cual vincular la academia a esta otra arquitectura. Revista de Arquitectura (Bogotá), 15(1), 120-130. Doi: http://dx.doi.org/10.14718/ RevArq.2013.15.1.13

Carvajalino, H. (2005). Hábitat popular y programas de mejoramiento: intervenir escenarios en proceso de consolidación. Invi, 20(53), 108-133. Recuperado de http://revistainvi.uchile.cl/index.php/INVI/article/view/ 336

Delgado, M. (1999). El animal público. Barcelona: Anagrama.

Espinoza, A. E. y Gómez, G. (2010). Hacia una concepción socio-física de la habitabilidad: espacialidad, sustentabilidad y sociedad. Revista Palapa, 1(10), 59-69. Recuperado de http:// www.redalyc.org/pdf/948/94820714006.pdf

Fique Pinto, L. F. (2009). El proyecto urbano-arquitectónico para un hábitat evolutivo de la población de bajos ingresos. Una reformulación de los problemas por abordar y de sus escenarios de actuación. En C. A. Torres Tovar (dir.) y M. Castillo de Herrera (ed.), Procesos urbanos informales y territorio: ensayos en torno a la construcción de sociedad, territorio y ciudad (pp. 245-262). Bogotá: Universidad Nacional de Colombia. Facultad de Artes. Maestría en Hábitat. Recuperado de http://www.facartes.unal.edu.co/ $\mathrm{fa} /$ institutos/ihct/publicaciones/procesos urbanos.pdf

Garzón, B., Auad, A., Abella, M. y Brañes, N. (2005). La transformación del hábitat popular desde talleres integrados de investigación acción participativa. Invi, 20(55), 121138. Recuperado de http://www.revistainvi. uchile.cl/index.php/INVI/article/view/321

Heidegger, M. (1993). Construir, habitar, pensar. En Ciencia y técnica. Santiago: Universidad Santiago de Chile.

Jaramillo, S. (2012). Urbanización informal: diagnósticos y políticas. Una revisión al debate latinoamericano para pensar líneas de acción actuales. Documentos CEDE, 11, 1-36. Recuperado de http://economia. uniandes.edu.co/publicaciones/dcede 2012-11.pdf
Jiménez Romera, C. y Torres Tovar, C. A. (2014). Proximidad obligada y densificación no planificada en Bogotá. Ciudades, 17(1), 121 138. Doi: https://doi.org/10.24197/ciudades.17.2014.121-138

Lezama, J. y Domínguez, J. (2006). Medio ambiente y sustentabilidad urbana. Papeles de Población, 12(49), 153-176. Recuperado de http://www.redalyc.org/pdf/112/11204 906.pdf

Leva, G. (2005). Indicadores de calidad de vida urbana. Teoría y metodología. Buenos Aires: Universidad Nacional de Quilmes. Recuperado de http://hm.unq.edu.ar/archivos_hm/ GL_ICVU.pdf

López Bernal, O. (2004). La sustentabilidad urbana. Bitácora urbano territorial, 1(8), 8-14. Recuperado de http://www.redalyc.org/pdf /748/74800801.pdf

López Valencia, A. y López, O. (2012). Conceptualización de un modelo de intervención urbana sostenible. Ecobarrios en el contexto latinoamericano de reciente industrialización. Revista de Arquitectura (Bogotá), 14(1), 116-127. Recuperado de https:// editorial.ucatolica.edu.co/ojsucatolica/ revistas_ucatolica/index.php/RevArq/article/view/732

Marulanda, L. (2000). El Biomanizales. Política ambiental local (IHS SINPA 11). SINPA Papers. Bolivia: Instituto de Estudios de Vivienda y Desarrollo Urbano (IHS). Recuperado de https://repub.eur.nl/pub/32226/

Naciones Unidas (2017). Plan de Acción Regional para la implementación de la Nueva Agenda Urbana en América Latina y el Caribe 2016-2036. Santiago de Chile: Naciones Unidas.

ONU-Habitat (2012). Estado de las ciudades de América Latina y el Caribe 2012. Rumbo a una nueva transición urbana. Nairobi: Onu-Habitat. Recuperado de http://mirror. unhabitat.org/pmss/getElectronicVersion. aspx? $\mathrm{nr}=3380 \&$ alt $=1$

ONU-Habitat (2016). Urbanización y desarrollo: futuros emergentes. Reporte Ciudades del Mundo. Nairobi: ONU-Habitat. Recuperado de http://nua.unhabitat.org/uploads/ Reportedelasciudades2016.pdf

Regolini, C. (2008). El conocimiento generador del proyecto urbano sostenible. Cuadernos de Investigación Urbanística Ci[Ur], 61, 1-116. Recuperado de http://polired.upm. es/index.php/ciur/article/view/277

Rincón Avellaneda, P. (2004). Análisis de los procesos de re-densificación en Bogotá, ¿una alternativa al crecimiento urbano sostenible? Bitácora Urbano Territorial, 1(8), 82-92. Recuperado de https://revistas.unal.edu.co/index.php/bitacora/article/ view/18760

Rueda, S. (2007). Libro verde de medio ambiente urbano. Tomo 1. Barcelona: Agencia de Ecología Urbana de Barcelona.

Saldaña, J. D. (2016). La rebelión urbana: ciudad informal y mejoramiento integral de barrios, dos realidades de la producción del espacio urbano residencial para la población de bajos ingresos en Bogotá (2000-2016). (Tesis de maestría). Universidad Nacional de Colombia. Bogotá. Recuperado de http://www.bdigital. unal.edu.co/52032/1/1018415212.2016.pdf

Sánchez Ruiz, J. E. (2009). El hábitat no es una cosa. En M. Echeverría Ramírez et al. ¿Qué es el hábitat?: las preguntas por el hábitat (pp. 117-140). Medellín: Universidad Nacional de Colombia sede Medellín. Escuela del hábitat CEHAP. Facultad de Arquitectura. Recuperado de http://www.bdigital.unal.edu. co/45777/1/Que_\%20es_\%20el_\%20habitat.pdf

Santos, M. (1996). Metamorfosis del espacio habitado. Barcelona: Oikos-Tau.

Techo (2015). Derecho a Bogotá. Informe de asentamientos informales. Recuperado de https://issuu.com/techocolombia/docs/ derecho_a_bogot

Torres Tovar, C. A. (coord.) y Grupo de Investigación Procesos Urbanos en Hábitat, Vivienda e Informalidad (2009a). Ciudad informal colombiana: barrios construidos por la gente. Bogotá: Universidad Nacional de Colombia, Facultad de Artes. Recuperado de http://www.facartes.unal.edu.co/fa/ institutos/ihct/publicaciones/ciudad informal.pdf

Torres Tovar, C. A. (2009b). El significado de la informalidad. Bitácora Urbano Territorial, 15(2), 7-12. Recuperado de https://revistas.unal.edu.co/index.php/bitacora/article/ view/18491

United Nations (2014). World Urbanization Prospects: The 2014 Revision [Highlights]. New York: Department of Economic and Social Affairs. Recuperado de https://esa.un.org/ unpd/wup/publications/files/wup2014-highlights.pdf

Villamizar, N. y Niño. G. (2009). Elementos para el desarrollo urbano sostenible en Colombia: los casos de Suluke, Turquía, y de las ciudades amazónicas, Colombia. Revista Alarife, 17, 19-38. Recuperado de https://www. researchgate.net/publication/43950161 Elementos_para_el_desarrollo_urbano_ sostenible en Colombia los casos de Sulukule_Tüquia_y_de_las_ciudades_āmazonicas_Colombia

Yory, C. (1998). Topofilia o la dimensión poética del habitar. Bogotá: CEJA.

Yunda, J. G. (2019). Densificación y estratificación social en Bogotá: distribución sesgada de la inversión privada. EURE, 45(134), 237-258 Recuperado de http://www.eure. $\mathrm{cl} /$ index.php/eure/article/view/2665 


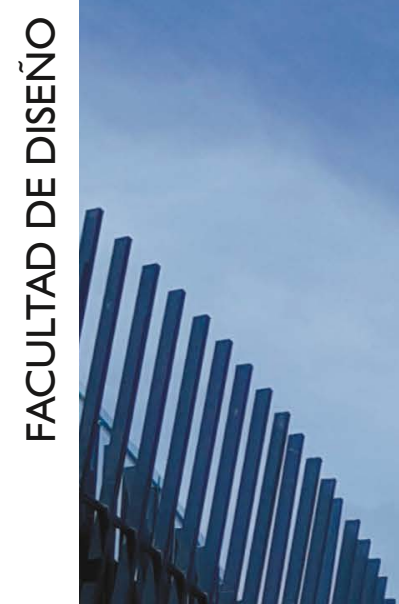

Vol.

\section{Nro. 1REVISTA DE ARQUITECTURA}
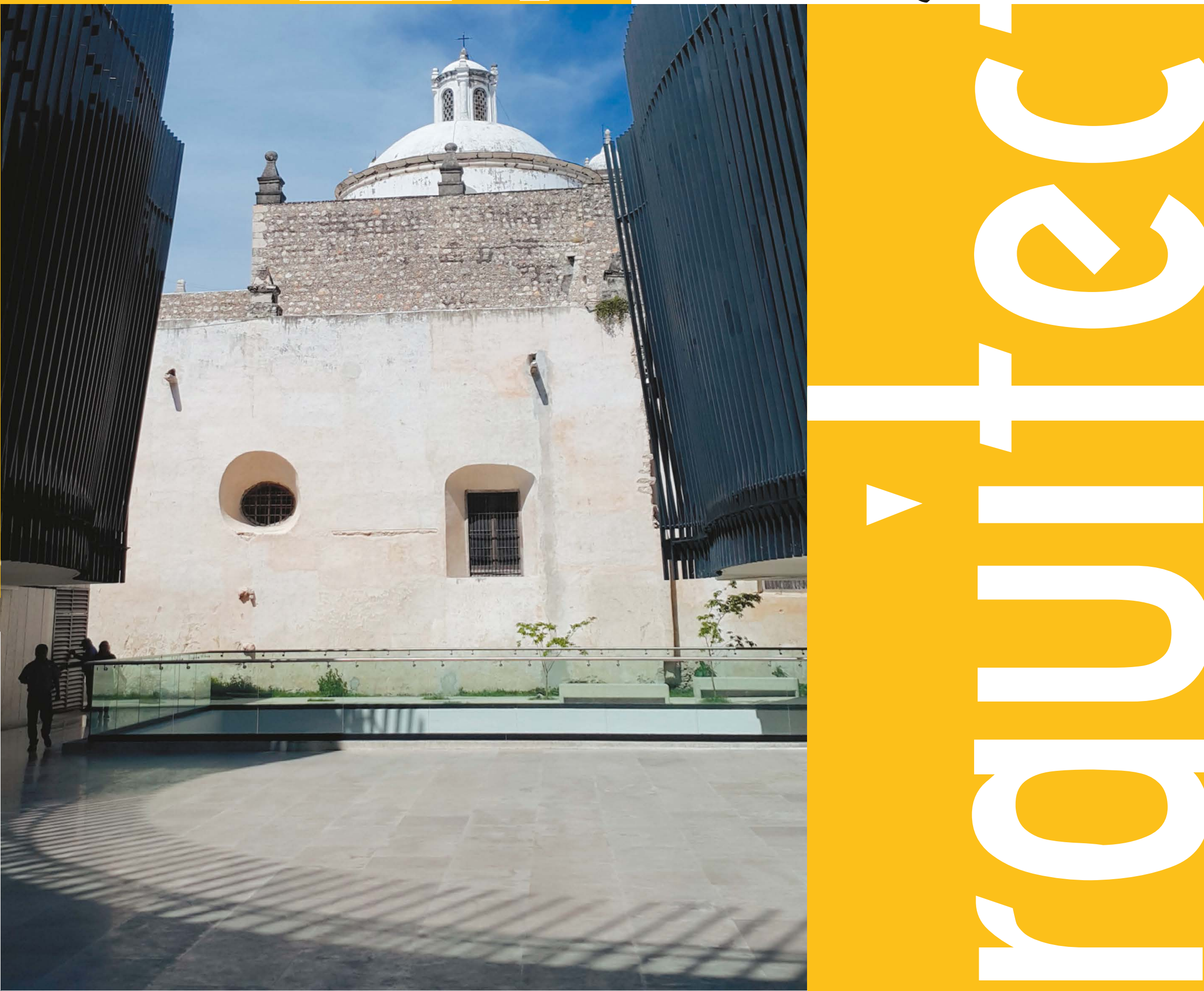
A) Portada: Palacio de la Música y Rectoria El J Júśs Tercera Orden. Mérida, Yucatán (México).

Fotografía: César Eligio-Triana (2018, septiembre) CC BY-NC

\section{(c) (1) ( $)$}

A Orientación editorial

\section{Enfoque y alcance}

La Revista de Arquitectura (Bogotá) ( (ISSN 1657-0308 Impresa y E-ISSN 2357-626X en línea) es una publicación seriada de acceso abierto, arbitrada mediante revisión por pares (doble ciego) e indexada, en donde se publican resultados de investigación originales e inéditos.

Está dirigida a la comunidad académica y profesional de las áreas afines a la disciplina. Es editada por la Facultad de Diseño y el Centro de Investigaciones (CIFAR) de la Universidad Católica de Colombia en Bogotá (Colombia).

La principal área científica a la que se adscribe la Revista de Arquitectura (Bogotá) según la OCDE es:

Gran área: 6. Humanidades

Área: 6.D. Arte

\section{Disciplina: 6D07. Arquitectura y Urbanismo}

También se publican artículos de las disciplinas como 2A02, Ingeniería arquitectónica; 5G03, Estudios urbanos (planificación y desarrollo); 6D07, Diseño.

Los objetivos de la Revista de Arquitectura (Bogotá) son:

- Promover la divulgación y difusión del conocimiento generado a nivel local, nacional e internacional

- Conformar un espacio para la construcción de comunidades académicas y la discusión en torno a las secciones definidas.

- Fomentar la diversidad institucional y geográfica de los autores que participan en la publicación.

- Potenciar la discusión de experiencias e intercambios científicos entre investigadores y profesionales.

- Contribuir a la visión integral de la arquitectura, por medio de la concurrencia y articulación de las secciones mediante la publicación de artículos de calidad.

- Publicar artículos originales e inéditos que han pasado por revisión de pares, para asegurar que se cumplen las normas éticas, de calidad, validez científica, editorial e investigativa.

- Fomentar la divulgación de las investigaciones y actividades desarrolladas en la Universidad Católica de Colombia.
Palabras clave de la Revista de Arquitectura (Bogotá): arquitectura, diseño, educación arquitectónica, proyecto y construcción, urbanismo.

Idiomas de publicación: español, inglés, portugués y francés. Título abreviado: Rev. Arquit.

\section{Titulo corto: RevArq}

\section{Políticas de sección}

La revista se estructura en tres secciones correspondientes a las líneas de investigación activas y aprobadas por la institución, y dos complementarias, que presentan dinámicas propias de la Facultad de Diseño y las publicaciones relacionadas con la disciplina.

Cultura y espacio urbano. En esta sección se publican los artículos que se refieren a fenómenos sociales en relación con el espacio urbano, atendiendo aspectos de la historia, el patrimonio cultural y físico, y la estructura formal de las ciudades y el territorio.

Proyecto arquitectónico y urbano. En esta sección se presentan artículos sobre el concepto de proyecto, entendido como elemento que define y orienta las condiciones proyectuales que devienen en los hechos arquitectónicos o urbanos, y la forma como estos se convierten en un proceso de investigación y nuevo de conocimiento. También se presentan proyectos que sean resultados de investigación, los cuales se validan por medio de la ejecución y transformación en obra construida del proceso investigativo. También se contempla la publicación de investigaciones relacionadas con la pedagogía y didáctica de la arquitectura, el urbanismo y el diseño.

Tecnología, medioambiente y sostenibilidad. En esta sección se presentan artículos acerca de sistemas estructurales, materiales y procesos constructivos, medioambiente y gestión, relacionados con los entornos social-cultural, ecológico y económico.

Desde la Facultad. En esta sección se publican artículos generados en la Facultad de Diseño, relacionados con las actividades de docencia, extensión, formación en investigación o internacionalización, las cuales son reflejo de la dinámica y de las actividades realizadas por docentes, estudiantes y egresados; esta sección no puede superar el $20 \%$ del contenido.

Textos. En esta sección se publican reseñas, traducciones y memorias de eventos relacionados con las publicaciones en Arquitectura y Urbanismo.

\section{A Frecuencia de publicación}

Desde 1999 y hasta el 2015, la Revista de Arquitectura (Bogotá) publicó un volumen al año, a partir del 2016 se publicarán dos números por año en periodo anticipado, enero-junio y julio-diciembre, pero también maneja la publicación anticipada en línea de los artículos aceptados (versión Post-print del autor).

La Revista de Arquitectura (Bogotá) se divulga mediante versiones digitales (PDF, HTML, EPUB, XML) e impresascon un tiraje de 700 ejemplares, los tiempos de producción de estas versiones dependerán de los cronogramas establecidos por la editorial.

Los tiempos de recepción-revisión-aceptación pueden tardar entre seis y doce meses dependiendo del flujo editorial de cada sección y del proceso de revisión y edición adelantado.

Con el usuario y contraseña asignados, los autores pueden ingresar a la plataforma de gestión editorial y verificar el estado de revisión, edición o publicación del artículo.
A Canje

La Revista de Arquitectura (Bogotá) está interesada en establecer canje con publicaciones académicas, profesionales o científicas del área de Arquitectura y Urbanismo, como medio de reconocimiento y discusión de la producción científica en el campo de acción de la publicación.

\section{Mecanismo}

Para establecer canje por favor descargar, diligenciar y enviar el formato: RevArq FP20 Canjes

\section{Universidad Católica de Colombia (2019, enero-junio). Revista de Arquitectura (Bogotá), $2 I(\mathrm{I})$ I-120. Doi: 10.14718 \\ ISSN: 1657-0308 E-ISSN: 2357-626X \\ Especificaciones: Formato: $34 \times 24 \mathrm{~cm}$ Papel: Mate $115 \mathrm{~g}$ Tintas: Negro y policromía}

A Contacto

Dirección postal:

Avenida Caracas No. 46-72.

Universidad Católica de Colombia

Bogotá D.C.(Colombia)

Código postal: 111311

Facultad de Diseño

Centro de Investigaciones (CIFAR).

Sede El Claustro. Bloque "L", 4 piso

Diag. 46a No. $15 b-10$

Editor, Arq. César Eligio-Triana

Teléfonos:

+57 (1) $3277300-3277333$

Ext. $3109 ; 3112$ o 5146

Fax: +57 (1) 2858895
Correo electrónico:

revistadearquitectura@ucatolica.edu.co

cifar@ucatolica.edu.co

Página WEB:

www.ucatolica edu.co

vínculo Revistas científicas

http://publicaciones.ucatolica.edu.co revistas-cientificas

http://editorial.ucatolica.edu.co/ojsucatolica/revistas_ucatolica/index.php/RevArq 
Universidad Católica de Colombia

Presidente

Édgar Gómez Betancourt

Vicepresidente - Rector

Francisco José Gómez Ortiz

Vicerrector Jurídico

Edwin de Jesús Horta Vásquez

Vicerrector Administrativo

Édgar Gómez Ortiz

Vicerrector Académico

Elvers Medellín Lozano

Vicerrector de Talento Humano

Ricardo López Blum

Director de Investigaciones

Edwin Daniel Durán Gaviria

Directora Editorial

Stella Valbuena García

\section{Facultad de Diseño}

Decano

Werner Gómez Benítez

Director de docencia

Jorge Gutiérrez Martínez

Directora de extensión

Mayerly Rosa Villar Lozano

Director de investigación

Hernando Verdugo Reyes

Director de gestión de calidad

Augusto Forero La Rotta

Comité asesor externo

Facultad de Diseño

Édgar Camacho Camacho

Martha Luz Salcedo Barrera

Samuel Ricardo Vélez
Facultad de Diseño

Centro de Investigaciones - CIFAR

\section{REVISTA DE ARQUITECTURA \\ Revista de Arquitectura \\ (Bogotá)}

Revista de acceso abierto,

arbitrada e indexada

Publindex: Categoría B. Índice Bibliográfico Nacional IBN.

Esci: Emerging Source Citation Index.

Doaj: Directory of Open Access Journals.

Redalyc: Red de Revistas Cientificas de América Latina y el Caribe,

España y Portugal.

SciELO: Scientific Electronic Library Online - Colombia

Redib: Red Iberoamericana de Innovación y Conocimiento Cientifico.

Ebsco: EBSCOhost Research Databases.

Clase: Base de datos bibliográfica de revistas de ciencias sociales y

humanidades.

Latindex: Sistema Regional de Información en Línea para Revistas

Científicas de América Latina, el Caribe, España y Portugal (Directorio

y catálogo).

Dialnet: Fundación Dialnet - Biblioteca de la Universidad de La Rioja.

LatinRev: Red Latinoamericana de Revistas Académicas en Ciencias

Sociales $y$ Humanidades.

Proquest: ProQuest Research Library.

Miar: Matrix for the Analysis of Journals.

Sapiens Research: Ranking de las mejores revistas colombianas según

visibilidad internacional.

Actualidad Iberoamericana: (Índice de Revistas) Centro de Información

Tecnológica (CIT).

Google Scholar

Arla: Asociación de Revistas latinoamericanas de Arquitectura.

\section{Editorial}

Av. Caracas № 46-72, piso 5

Teléfono: 3277300 Ext. 5145

editorial@ucatolica.edu.co

www.ucatolica.edu.co

http://publicaciones.ucatolica.edu.co)

Impresión:

JaVEGRAF

Calle 46A No82-54 Int. 2

Bogotá, D. C., Colombia

http://www.javegraf.com.co/index.php

Enero de 2019
Director

Werner Gómez Benítez

Editor

César Eligio-Triana

Editores de sección

(1) Myriam Stella Díaz-Osorio

(1) Carolina Rodríguez-Ahumada

(4) Anna Maria Cereghino-Fedrigo

\section{Equipo editorial}

Coordinadora editorial

María Paula Godoy Casasbuenas

mpgodoy@ucatolica.edu.co

Diseño y montaje

Juanita Isaza

juanaisaza@gmail.com

Traductoras

Inglés

Erika Tanacs

etanacs25@gmail.com

Portugués

Roanita Dalpiaz

roanitad@gmail.com

Correctora de estilo

María José Díaz Granados M.

mariajose_dgm@yahoo.com.co

Página Web

Centro de investigaciones (CIFAR)

Distribución y canjes

Claudia Álvarez Duquino

calvarez@ucatolica.edu.co
Comité editorial y científico

Cultura y espacio urbano

Carlos Mario Yory, PhD

Universidad Católica de Colombia. Bogotá, Colombia

Sonia Berjman, $\mathrm{PhD}$

ICOMOS-IFLA, Buenos Aires, Argentina

Juan Carlos Pérgolis, MSc Universidad Piloto de Colombia. Bogotá, Colombia

Beatriz García Moreno, PhD

Universidad Nacional de Colombia. Bogotá, Colombia

Proyecto arquitectónico y urbano

Jean-Philippe Garric, PhD, HDR

Université Paris I Panthéon-Sorbonne. Paris, Francia

Debora Domingo Calabuig, PhD

Universidad Politécnica de Valencia, España

Dania González Couret, PhD

Universidad Tecnológica de La Habana, Cuba

Hugo Mondragón López, PhD Pontificia Universidad Católica de Chile. Santiago, Chile

Juan Pablo Duque Cañas, PhD

Universidad Nacional de Colombia. Bogotá, Colombia

Tecnología, medioambiente y sostenibilidad

Mariano Vázquez Espí, PhD

Universidad Politécnica de Madrid, España

Denise Helena Silva Duarte, PhD Universidade de São Paulo (USP), Brasil

Luis Carlos Herrera Sosa, PhD Universidad Autónoma de Ciudad Juárez, México

Claudio Varini, PhD

Universidad Católica de Colombia. Bogotá, Colombia

Luis Gabriel Gómez Azpeitia, PhD Universidad de Colima. Colima, México 


\section{CONTENIDO}
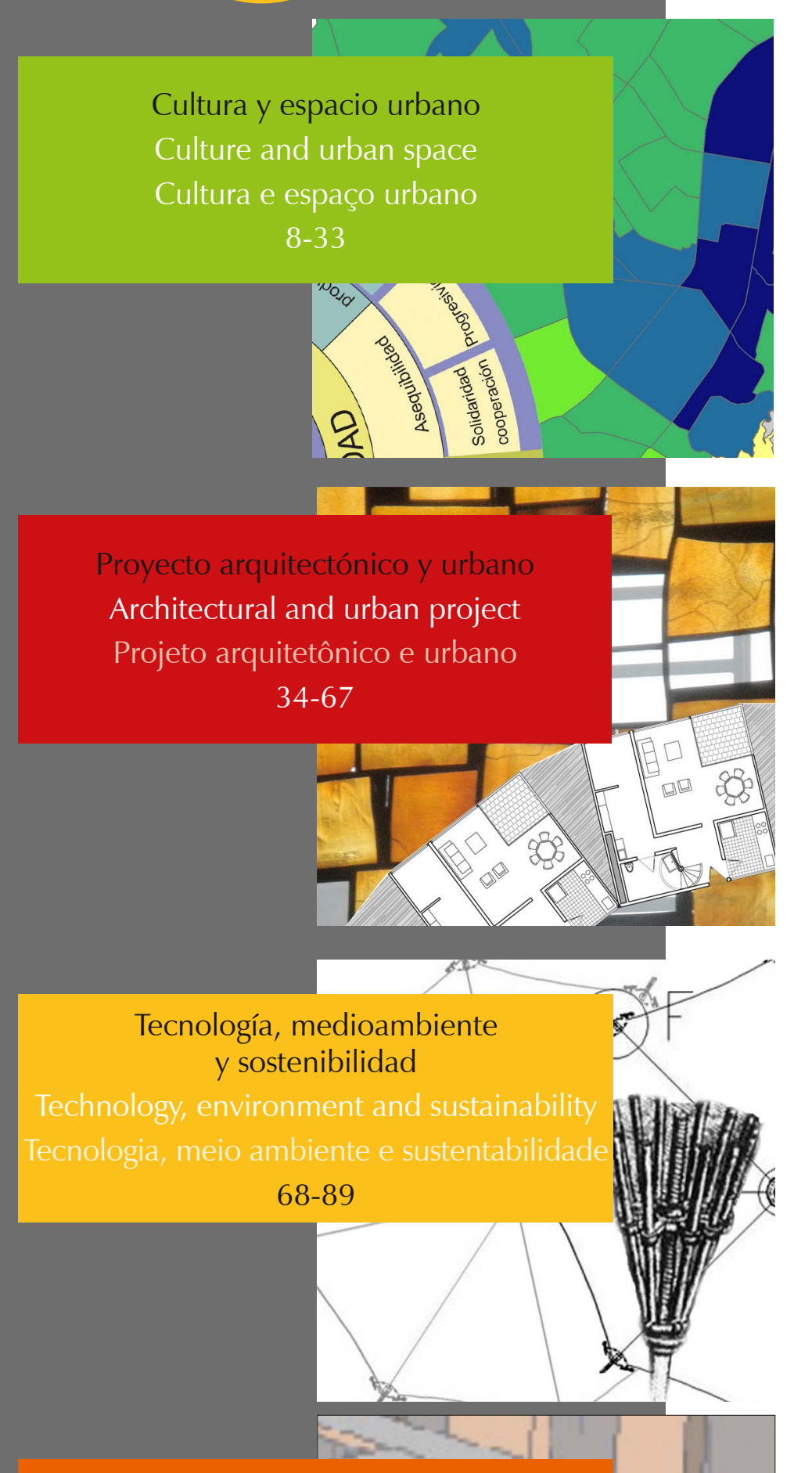

Desde la Facultad

From the Faculty

Da faculdade

90-109

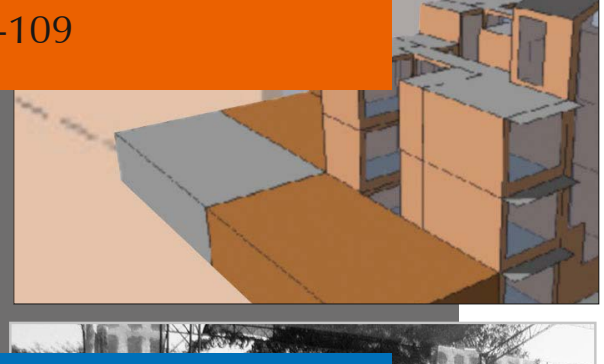

Textos

Texts

Textos

110-118
Revistas en tiempos tecno-humanos

Julio Arroyo

Pág. 3

ES

Índice de caminabilidad para la ciudad de Bogotá

Julián Alberto Gutiérrez-López
Yolanda Beatriz Caballero-Pérez
Rubén Alejandro Escamilla-Triana

ES

Pág. 8

Principios, criterios y propósitos de desarrollo sustentable para la redensificación en contextos urbanos informales
Juan José Castiblanco-Prieto
Fabián Adolfo Aguilera-Martínez
Fabián Alonso Sarmiento-Valdés

Pág. 21

ES

Complejidad y constructivismo en la nueva tradición de la arquitectura de la posguerra

Francisco Javier Fuentes-Farías

Pág. 34 ES

Conservación del arte contemporáneo

El caso de Mathias Goeritz en la Catedral

Metropolitana de México

Alberto Cedeño-Valdiviezo

Pablo Torres-Lima

Pág. 44

\section{ES EN}

Operando desde la forma: un procedimiento

para la valoración de la vivienda colectiva

Julián Camilo Valderrama-Vidal

Pág. 54

ES

Disponibilidad de las técnicas constructivas

de habitación en madera, en Brasil

Victor A. De Araujo

Carlos M. Gutiérrez-Aguilar

Juliana Cortez-Barbosa

Maristela Gava

José N. Garcia

Pág. 68

ES

Diseño y construcción de un paraguas plegable para espacios arquitectónicos

Carlos César Morales-Guzmán

Pág. 76

ES EN

Envolventes eficientes

Relación entre condiciones ambientales, espacios confortables

y simulaciones digitales

Natalia Medina-Patrón

Jonathan Escobar-Saiz

Pág. 90

ES

(Re)pensando el enfoque tecnológico:

el caso del Centro Experimental de la Vivienda

Económica (CEVE) en Argentina

Gustavo Pelegrin

Laila Fleker

Aurelio Ferrero

Pág.110 
La postulación de un artículo a la Revista de Arquitectura (Bogotá) indica que- el o los autores certifican que conocen y aceptan la política editorial, para lo cual firmarán en original y remitirán el formato RevArq FP00 Carta de originalidad.

La Revista de Arquitectura (Bogotá) maneja una política de Autoarchivo VERDE, según las directrices de SHERPA/RoMEO, por lo cual el autor puede:

- Pre-print del autor: Archivar la versión pre-print (la versión previa a la revisión por pares

- Post-print del autor: Archivar la versión post-print (la versión final posterior a la revisión por pares

- Versión de editor/PDF: Archivar la versión del editor - PDF/HTML/XLM en la maqueta de la Revista de Arquitectura (Bogotá).

El Autoarchivo se debe hacer respetando la licencia de acceso abierto, la integridad y la imagen de la Revista de Arquitectura (Bogotá), también se recomienda incluir la referencia, el vínculo electrónico y el DOI.

El autor o los autores son los titulares del Copyright (c) del texto publicado y la Editorial de la Revista de Arquitectura (Bogotá) solicita la firma de una autorización de reproducción del artículo (RevArq FP03 Autorización reproducción), la cual se acoge a la licencia CC, donde se expresa el derecho de primera publicación de la obra.

La Revista de Arquitectura (Bogotá) se guía por las normas internacionales sobre propiedad intelectual y derechos de autor, y de manera particular el artículo 58 de la Constitución Política de Colombia, la Ley 23 de 1982 y el Acuerdo 172 del 30 de septiembre de 2010 (Reglamento de propiedad intelectual de la Universidad Católica de Colombia)

Para efectos de autoría y coautoría de artículos se diferencian dos tipos: "obra en colaboración" y "obra colectiva". La primera es aquella cuya autoría corresponde a todos los participantes al ser fruto de su trabajo conjunto. En este caso, quien actúa como responsable y persona de contacto debe asegurar que quienes firman como autores han revisado y aprobado la versión final, y dan consentimiento para su divulgación. La obra colectiva es aquella en la que, aunque participan diversos colaboradores, hay un autor que toma la iniciativa la coordinación y realización de dicha obra. En estos casos, la autoría corresponderá a dicha persona (salvo pacto en contrario) y será suficiente únicamente con su autorización de divulgación.

El número de autores por artículo debe estar justificado por el tema, la complejidad y la extensión, y no deberá ser superior a la media de la disciplina, por lo cual se recomienda que no sea mayor de cinco. El orden en que se enuncien corresponderá a los aportes de cada uno a la construcción del texto, se debe evitar la autoría ficticia o regalada. Si se incluyen más personas que trabajaron en la investigación se sugiere que sea en calidad de colaboradores o como parte de los agradecimientos. La Revista de Arquitectura (Bogotá) respetará el número y el orden en que figuren en el original remitido. Si los autores consideran necesario, al final del artículo pueden incluir una breve descripción de los aportes individuales de cada uno de firmantes.

La comunicación se establece con uno de los autores, quien a su vez será el responsable de informar a los demás autores de las notificaciones emitidas por la Revista de Arquitectura (Bogotá).

En virtud de mantener el equilibro de las secciones y las mismas oportunidades para todos los participantes, un mismo autor puede postular dos o más artículos de manera simultánea; si la decisión editorial es favorable y los artículos son aceptados, su publicación se realizará en números diferentes.

\section{A Acceso abierto}

La Revista de Arquitectura (Bogotá), en su misión de divulgar la investigación y apoyar el conocimiento y la discusión en los campos de interés, proporciona acceso abierto, inmediato e irrestricto a su contenido de manera gratuita mediante la distribución de ejemplares impresos y digitales. Los interesados pueden leer, descargar, guardar, copiar y distribuir, imprimir, usar, buscar o referenciar el texto completo o parcial de los artículos o la totalidad de la Revista de Arquitectura (Bogotá).

\section{(c) (1) (3)}

Esta revista se acoge a la licencia Creative Commons (CC BY NC de Atribución - No comercial 4.0 Internacional): "Esta licencia permite a otros entremezclar, ajustar y construir a partir de su obra con fines no comerciales, y aunque en sus nuevas creaciones deban reconocerle su autoría y no puedan ser utilizadas de manera comercial, no tienen que estar bajo una licencia con los mismos términos".

La Revista de Arquitectura es divulgada en centros y grupos de investigación, en bibliotecas y universidades, y en las principales facultades de Arquitectura mediante acceso abierto a la versión digital y suscripción anual al ejemplar impreso o por medio de canje, este último se formaliza mediante el formato RevArq FP20 Canjes

Para aumentar su visibilidad y el impacto de los artículos, se envían a bases de datos y sistemas de indexación y resumen (SIR) y, asimismo, pueden ser consultados y descargados en la página web de la revista.

La Revista de Arquitectura no maneja cobros, tarifas o tasas de publicación de artículo (Article Processing Charge-APC), o por el sometimiento de textos a la publicación.

\section{(A) Ética y buenas prácticas}

La Revista de Arquitectura se compromete a cumplir y respetar las normas éticas en todas las etapas del proceso de publicación. Los autores de los artículos publicados darán cumplimiento a los principios éticos contenidos en las diferentes declaraciones y legislaciones sobre propiedad intelectual y derechos de autor específicos del país donde se realizó la investigación. En consecuencia, los autores de los artículos postulados y aceptados para publicar, que presentan resultados de investigación, deben firmar la declaración de originalidad (formato RevArq FP00 Carta de originalidad).

La Revista de Arquitectura reconoce y adopta los principios de transparencia y buenas prácticas descritos por COPE, "Principles of Transparency and Best Practice in Scholarly Publishing" (2015).

El equipo editorial tiene la obligación de guardar la confidencialidad acerca de los artículos recibidos, y abstenerse de usar en sus propias investigaciones datos, argumentos o interpretaciones hasta tanto el artículo no sea publicado. También debe ser imparcial y gestionar los artículos de manera adecuada y en los plazos establecidos. La selección de revisores se hará con objetividad y estos deberán responder a la temática del artículo.

El editor, los autores y los revisores deben seguir las normas éticas internacionales definidas por el Committee on Publication Ethics (COPE), con el fin de evitar casos de:

- Fabricación, falsificación u omisión de datos.

- Plagio y autoplagio.

- Publicación redundante, duplicada o fragmentada.

- Omisión de referencias a las fuentes consultadas.

- Utilización de contenidos sin permiso o sin justificación.

- Apropiación individual de autoría colectiva.

- Cambios de autoría.

- Conflicto de interés (CDI) no revelado o declarado.

- Otras que pudieran surgir en el proceso de investigación y publicación. La fabricación de resultados se genera al mostrar datos inventados por los autores; la falsificación resulta cuando los datos son manipulados y cambiados a capricho de los autores; la omisión se origina cuando los autores ocultan deliberadamente un hecho o dato. El plagio se da cuando un autor presenta como ideas propias datos creados por otros. Los casos de plagio son los siguientes: copia directa de un texto sin entrecomillar o citar la fuente, modificación de algunas palabras del texto, paráfrasis y falta de agradecimientos; el autoplagio se da cuando el mismo autor reutiliza material propio que ya fue publicado, pero sin indicar la referencia al trabajo anterior. La revista se apoya en herramientas digitales que detectan cualquiera de estos casos en los artículos postulados, y es labor de los editores y revisores velar por la originalidad y fidelidad en la citación. La publicación redundante o duplicada se refiere a la copia total, parcial o alterada de un trabajo ya publicado por el mismo autor

En caso de sospechar de alguna mala conducta se recomienda seguir los diagramas de flujo elaborados por COPE (2008), con el fin de determinar las acciones correspondientes.

La Revista de Arquitectura se reserva el derecho de retractación de publicación de aquellos artículos que, posterior a su publicación, se demuestre que presentan errores de buena fe, o cometieron fraudes o malas prácticas científicas. Esta decisión se apoyará en "Retraction Guidelines" (COPE, 2009). Si el error es menor, este se podrá rectificar mediante una nota editorial de corrección o una fe de erratas. Los autores también tienen la posibilidad de solicitar la retractación de publicación cuando descubran que su trabajo presenta errores graves. En todos los casos se conservará la versión electrónica y se harán las advertencias de forma clara e inequívoca.

\section{A Privacidad y manejo de la información.} Habeas Data

Para dar cumplimiento a lo previsto en el artículo 10 del Decreto 1377 de 2013, reglamentario de la Ley 1581 de 2012, y según el Acuerdo 002 del 4 de septiembre de 2013 de la Universidad Católica de Colombia, "por el cual se aprueba el manual de políticas de tratamiento de datos personales":

La Universidad Católica de Colombia, considerada como responsable o encargada del tratamiento de datos personales, manifiesta que los datos personales de los autores, integrantes de los comités y pares revisores, se encuentran incluidos en nuestras bases de datos; por lo anterior, y en cumplimiento de las disposiciones legales vigentes, la Universidad solicitará siempre su autorización, para que en desarrollo de sus funciones propias como Institución de Educación Superior, en especial las relacionadas con la docencia, la extensión y la investigación, la Universidad Católica de Colombia pueda recolectar, recaudar, almacenar, usar, circular, suprimir, procesar, intercambiar, compilar, dar tratamiento, actualizar, transmitir o transferir a terceros países y disponer de los datos que le han suministrado y que han sido incorporados en las bases de datos de todo tipo que reposan en la Universidad.

La Universidad Católica de Colombia queda autorizada, de manera expresa e inequívoca, en los términos señalados por el Decreto 1377 de 2013, para mantener y manejar la información de nuestros colaboradores (autores, integrantes de los diferentes comités y pares revisores); así mismo, los colaboradores podrán ejercer sus derechos a conocer, actualizar, rectificar y suprimir sus datos personales, para lo cual se han dispuesto las siguientes cuentas de correo electrónico: 
La Revista de Arquitectura (Bogotá) recibe artículos de manera permanente. Los artículos se procesan a medida que se postulan, dependiendo el flujo editorial de cada sección.

El idioma principal es el español, y como opcionales están definidos el inglés, el portugués y el francés; los textos pueden ser escritos y presentados en cualquiera de estos.

Los artículos postulados deben corresponder a las categorías universalmente aceptadas como producto de investigación, ser originales e inéditos y sus contenidos responder a criterios de precisión, claridad y brevedad.

Como punto de referencia se pueden tomar las tipologías y definiciones del Îndice Bibliográfico Nacional, Publindex (2010) que se describen la continuación:

1. Artículo de revisión: documento resultado de una investigación terminada donde se analizan, sistematizan e integran los resultados de investigaciones publicadas o no publicadas, sobre un campo en ciencia o tecnología, con el fin de dar cuenta de los avances y las tendencias de desarrollo. Se caracteriza por presentar una cuidadosa revisión bibliográfica de por lo menos 50 referencias.
2. Artículo de investigación científica y tecnológica: documento que presenta, de manera detallada, los resultados originales de proyectos terminados de investigación. La estructura generalmente utilizada contiene cuatro apartes importantes: introducción, metodología, resultados y conclusiones.

3. Artículo de reflexión: documento que presenta resultados de investigación terminada desde una perspectiva analítica, interpretativa o crítica del autor, sobre un tema específico, recurriendo a fuentes originales.

Adicional a estas tipologías, se pueden presentar otro tipo de artículos asociados a procesos de investigación-creación y/o investigación proyectual. En todos los casos se debe presentar la información suficiente para que cualquier investigador pueda reproducir la investigación y confirmar o refutar las interpretaciones defendidas y sea evidente el aporte a la disciplina.

En todos los casos se debe presentar la información suficiente para que cualquier investigador pueda reproducir la investigación y confirmar o refutar las interpretaciones defendidas.

\section{(A) Instrucciones para postular artículos}

Postular el artículo en la página web de la Revista de Arquitectura (Bogotá) y adjuntar comunicación escrita dirigida al editor RevArq_FP00 Carta de originalidad (debidamente firmada por todos los autores en original); de igual manera, se debe diligenciar el formato de hoja de vida RevArq FP01 Hoja de Vida (una por cada autor).

En la comunicación escrita el autor expresa que conoce y acepta la política editorial de la Revista de Arquitectura (Bogotá), que el artículo no está postulado para publicación simultáneamente en otras revistas u órganos editoriales y que no existe conflicto de intereses (ver modelo RevArq FP06 CDI) y que, de ser aceptado, concederá permiso de primera publicación, no exclusiva a nombre de la Universidad Católica de Colombia como editora de la revista.

Los artículos deben tener en cuenta las siguientes recomendaciones:

- En la primera página del documento se debe incluir:

Tírulo: no exceder 15 palabras

Subtítulo: opcional, complementa el título o indica las principales subdivisiones del texto.

Nombre del autor o autores: nombres y apellidos completos o según modelo de citación adoptado por el autor para la normalización de los nombres del investigador. Como nota al pie (máximo 100 palabras) formación académica, experiencia profesional e investigativa, código ORCID https://orcid.org/, e información de contacto, correo electrónico.

Filiación institucional: debajo del nombre se debe declarar la ins-titución en la cual se desarrolló el producto, de la cual recibió apoyo o aquella que respalda el trabajo investigativo.

Resumen: debe ser analítico, se redacta en un solo párrafo, da cuenta del tema, el objetivo, la metodología, los resultados y las conclusiones; no debe exceder las 150 palabras.

Palabras clave: cinco palabras o grupo de palabras, ordenadas alfabéticamente y que no se encuentren en el título o subtítulo; estas sirven para clasificar temáticamente al artículo. Se recomienda emplear principalmente palabras definidas en el tesauro de la Unesco (http://databases. unesco.org/thessp/), en el tesauro de Arte \& Arquitectura (C) (www.aatespanol.cl), o Vitruvio (http://vocabularyserver.com/vitruvio/)

También se recomienda incluir título, resumen y palabras clave en segundo idioma.

- La segunda página y siguientes deben tener en cuenta:

El cuerpo del artículo se divide en: Introducción, Metodología, Resultados y Discusión de resultados; posteriormente se presentan las Conclusiones, y luego las Referencias bibliográficas y los Anexos (modelo IMRYD). Las tablas y figuras se deben incorporar en el texto.

Descripción del proyecto de investigación: en la introducción se debe describir el tipo de artículo y brevemente el marco investigativo del cual es resultado y diligenciar el formato (RevArq FP02 Info Proyectos de Investigación).

TEXTO: todas las páginas deben venir numeradas y con el título de artículo en la parte superior de la página. Márgenes de $3 \mathrm{~cm}$ por todos los lados, interlineado doble, fuente Arial o Times New Roman de 12 puntos, texto justificado (Ver plantilla para presentación de artículos). La extensión de los artículos debe ser de alrededor de 5.000 palabras ( \pm 20 páginas, incluyendo gráficos, tablas, referencias, etc.); como mínimo 3.500 y máximo 8.000 palabras. Se debe seguir el estilo vigente y recomendado en el Manual para Publicación de la American Psychological Association (APA). (Para mayor información véase http://www.apastyle.org/)
Citas y notas al pie: las notas aclaratorias o notas al pie no deben exceder cinco líneas o 40 palabras, de lo contrario estas deben ser incorporadas al texto general. Las citas pueden ser:

Corta: (con menos de 40 palabras) se incorporan al texto y pueden ser: textuales (se encierran entre dobles comillas), parafraseo o resumen (se escriben en palabras del autor dentro del texto).

Cita textual extensa: (mayor de 40 palabras) debe ser dispuesta en un renglón y un bloque independiente con sangrías y omitiendo las comillas, no olvidar en ningún caso la referencia del autor (Apellido, año, página).

Referencias: como modelo para la construcción de referencias se emplea el estilo recomendado en el Manual para Publicación de la American Psychological Association (APA) (http://www.apastyle.org/).

Siglas: en caso de emplear siglas en el texto, las figuras o las tablas, se debe proporcionar la equivalencia completa la primera vez que se empleen y encerrarlas entre paréntesis. En el caso de citar personajes reconocidos se deben colocar nombres o apellidos completos, nunca emplear abreviaturas.

Figuras y tablas: las figuras (gráficos, diagramas, ilustraciones, planos, mapas o fotografías) y las tablas deben ir numeradas y contener título o leyenda explicativa relacionada con el tema del artículo, que no exceda las 15 palabras (Figura 1. xxxxx, Tabla 1. xxxx, etc.) y la procedencia (fuente: autor o fuente, año, página). Estas se deben referenciar en el texto de forma directa o entre paréntesis; se recomienda hacerlo con referencias cruzadas.

También se deben entregar en medio digital, independiente del texto, en formatos editables o abiertos. La marcación de los archivos debe corresponder a la incluida en el texto. Según la extensión del artículo se deben incluir de 5 a 10 gráficos. Ver guía para la búsqueda de imágenes de dominio público o bajo licencias Creative Commons (CC).

El autor es el responsable de adquirir los derechos o las autorizaciones de reproducción a que haya lugar para imágenes o gráficos tomados de otras fuentes, así como de entrevistas o material generado por colaboradores diferentes a los autores; de igual manera, se debe garantizar la protección de datos e identidades para los casos que sea necesario.

FotografíA: pueden ser entregadas en original para ser digitalizadas, de lo contrario se deben digitalizar con una resolución igual o superior a 300 dpi para imágenes a color y 600 para escala de grises. Los formatos de las imágenes pueden ser TIFF, PSD o JPG, y deben cumplir con las características expresadas en el punto anterior (figuras).

Planimetría: se debe entregar la planimetría original en medio digital, en lo posible en formato CAD, y sus respectivos archivos de plumas o en PDF; de no ser posible, se deben hacer impresiones en tamaño carta con las referencias de los espacios mediante numeración y lista adjunta. Deben tener escala gráfica, escala numérica, norte, coordenadas y localización. En lo posible, no deben contener textos, achurados o tramas.

Para más detalles, consultar el documento RevArq Parámetros para Autores Descripción en el portal web de la Revista de Arquitectura (Bogotá)

\section{Beneficios}

Como reconocimiento a los autores, se les hará envío postal de dos ejemplares de la edición impresa sin ningún costo y entregada en la dirección consignada en el formato de hoja de vida (RevArq FP01); adicionalmente, se enviará el vínculo para la descarga de la versión digital.

También se enviará una constancia informativa en la que se relaciona la publicación del artículo y, de manera opcional, se pueden detallar las fechas del proceso editorial y el arbitraje realizado. 
La selección de revisores se realiza de acuerdo con los siguientes criterios:

- Afinidad temática.

- Formación académica.

- Experiencia investigativa y profesional.

- Producción editorial en revistas similares o en libros resultado de investigación.

El proceso de arbitraje se basa en los principios de equidad e imparcialidad, y en los criterios de calidad y pertinencia.

El desarrollo de la revisión se realiza según el formato (RevArq FP10 Evaluación de artículos) y las observaciones que el revisor considere necesarias en el cuerpo del artículo. En cualquiera de los conceptos que emita el revisor (Aceptar, Publicable con modificaciones, Reevaluable o No publicable), y como parte de la labor formativa y de comunidad académica, el revisor hará sugerencias para mejorar et documento. El revisor podrá solicitar una nueva relectura del artículo después de los ajustes realizados por el autor.

El revisor también deberá diligenciar el formato RevArq FP01 Hoja de Vida, con el fin de certificar y soportar el proceso de revisión ante los SIR que así lo soliciten.

En el proceso de arbitraje se emplea el método doble ciego, los nombres del revisor no serán conocidos por el autor y viceversa. Con el fin de garantizar el anonimato del autor, al artículo postulado se le han podido suprimir nombres, instituciones o imágenes que puedan ser asociadas de manera directa al autor.

Aunque se procura el anonimato, una vez recibida la invitación como par revisor del artículo, el revisor debe cerciorarse de que no exista conflicto de intereses (CDI) o alguna limitante que afecte la revisión o que pueda ser vista como tal (lazos familiares, amistad o enemistad, vínculos contractuales o laborales, posiciones éticas, etc.), de presentarse esta situación se notificara al editor. (Ver modelo RevArq FP06 CDI).

Dada la confidencialidad del proceso de revisión, y considerando los derechos de autor y de propiedad intelectual que pueda haber sobre el material que se entrega, el revisor se compromete a mantener en absoluta reserva su labor, a limitar el uso de la obra entregada solo para el propósito designado y a devolver la documentación remitida una vez concluya la actividad.

El tiempo establecido para las revisiones de pares es de máximo un mes a partir de la confirmación de la recepción de la documentación. Ese plazo podrá ser modificado de mutuo acuerdo entre e editor y el revisor, siempre y cuando no afecte la periodicidad de la revista, la impresión o el tiempo para emitir una respuesta al autor.

Los revisores se acogerán a "COPE Ethical Guidelines for Peer Reviewers" de COPE.

\section{Beneficios}

Como retribución a los revisores se les hará envío postal de un ejemplar de la edición impresa sin ningún costo y entregada en la dirección consignada en el formato de hoja de vida. También, si es de interés para el revisor, podrá hacer la solicitud de alguna de las publicaciones editadas y presentes en el catálogo de publicaciones de la UNIVERSIDAD CATÓLICA DE COLOMBIA, previa aprobación de la Editorial y sujeto a la disponibilidad.

Si lo desea tendrá derecho a una constancia de la colaboración en la revisión de artículos, la cual solo contendrá el periodo en el cual se realizó la actividad. También tendrá la posibilidad de aceptar o no la publicación de su nombre, nacionalidad y nivel máximo de formación en la página web de la Revista de Arquitectura (Bogotá) en su calidad de colaborador.

\section{A Proceso de revisión por pares}

Luego de la postulación del artículo, el editor de la Revista de Arquitectura (Bogotá) selecciona y clasifica los artículos que cumplen con los requisitos establecidos en las directrices para los autores. El editor podrá rechazar en primera instancia artículos, sin recurrir a un proceso de revisión, si los considera de baja calidad o por presentar evidencias de faltas éticas o documentación incompleta.

Los artículos se someterán a un primer dictamen del editor, de los editores de sección y del Comité Editorial, teniendo en cuenta:

- Afinidad temática, relevancia del tema y correspondencia con las secciones definidas.

- Respaldo investigativo.

- Coherencia en el desarrollo del artículo, así como una correcta redacción y ortografía.

- Relación entre las figuras y tablas con el texto del artículo.
En esta revisión se verificará el nivel de originalidad mediante el uso de software especializado (Ithenticate o similar) y recursos digitales existentes para tal fin, también se observará la coherencia y claridad en los apartados del documento (modelo IMRYD), la calidad de las fuentes y la adecuada citación, esto quedará consignado en el formato (RevArq FP09 Revisión de artículos); esta información será cargada a la plataforma de gestión editorial y estará a disposición del autor.

En caso de que el artículo requiera ajustes preliminares, será devuelto al autor antes de ser remitido a revisores. En este caso, el autor tendrá veinte días para remitir nuevamente el texto con los ajustes solicitados.

Después de la preselección se asignan mínimo dos revisores especializados, quienes emitirán su concepto utilizando el formato (RevArq FP10 Evaluación de artículos) y las anotaciones que consideren oportunas en el texto; en esta etapa se garantizará la confidencialidad y el anonimato de autores y revisores (modalidad doble ciego).

Del proceso de revisión se emite uno de los siguientes conceptos que será reportado al autor:

\section{- Aceptar el envío: con o sin observaciones.}

- Publicable con modificaciones: se podrá sugerir la forma más adecuada para una nueva presentación, el autor puede o no aceptar las observaciones según sus argumentos. Si las acepta, cuenta con quince días para realizar los ajustes pertinentes.

- Reevaluable: cumple con algunos criterios y debe ser corregido. Es necesario hacer modificaciones puntuales y estructurales al artículo. En este caso, el revisor puede aceptar o rechazar hacer una nueva lectura del artículo luego de ajustado.

- No publicable: el autor puede volver a postular el artículo e iniciar nuevamente el proceso de arbitraje, siempre y cuando se evidencien los ajustes correspondientes.

En el caso de presentarse diferencias sustanciales y contradictorias en los conceptos sobre la recomendación del revisor, el editor remitirá el artículo a un revisor más o a un miembro del Comité Editorial quien podrá actuar como tercer árbitro, con el fin de tomar una decisión editorial sobre la publicación del artículo.

Los autores deberán considerar las observaciones de los revisores o de los editores, y cada corrección incorporada u omitida debe quedar justificada en el texto o en una comunicación adjunta. En el caso que los autores omitan las indicaciones realizadas sin una argumentación adecuada, el artículo será devuelto y no se dará por recibido hasta que no exista claridad al respecto.

El editor respetará la independencia intelectual de los autores y a estos se les brindará el derecho de réplica en caso de que los artículos hayan sido evaluados negativamente y rechazados.

Los autores, con su usuario y contraseña, podrán ingresar a la plataforma de Gestión Editorial, donde encontrarán los conceptos emitidos y la decisición sobre el artículo.

El editor y el Comité Editorial se reservan el derecho de aceptar o no la publicación del material recibido. También se reservan el derecho de sugerir modificaciones de forma, ajustar las palabras clave o el resumen y de realizar la corrección de estilo. El autor conocerá la versión final del texto antes de la publicación oficial del mismo.

Cuando un artículo es aceptado para su publicación, el autor debe firmar la autorización de reproducción (RevArq FP03 Autorización reproducción). Para más información ver: Política de derechos de autor

\section{Notas aclaratorias:}

La Revista de Arquitectura (Bogotá) busca el equilibrio entre las secciones, motivo por el cual, aunque un artículo sea aceptado o continúe en proceso de revisión, podrá quedar aplazado para ser publicado en un próximo número; en este caso, el autor estará en la posibilidad de retirar la postulación del artículo o de incluirlo en el banco de artículos del próximo número.

El editor y los editores de sección de la Revista de Arquitectura (Bogotá) son los encargados de establecer contacto entre los autores y revisores, ya que estos procesos se realizan de manera anónima.
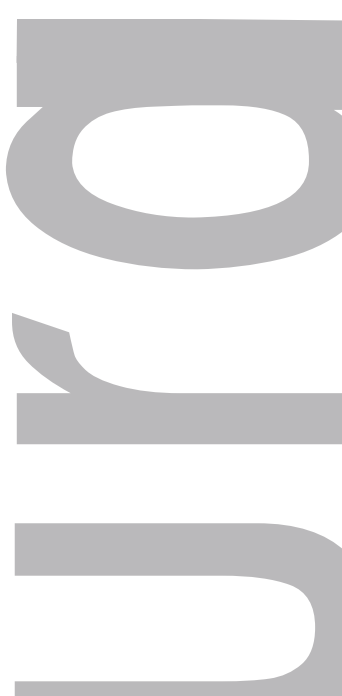
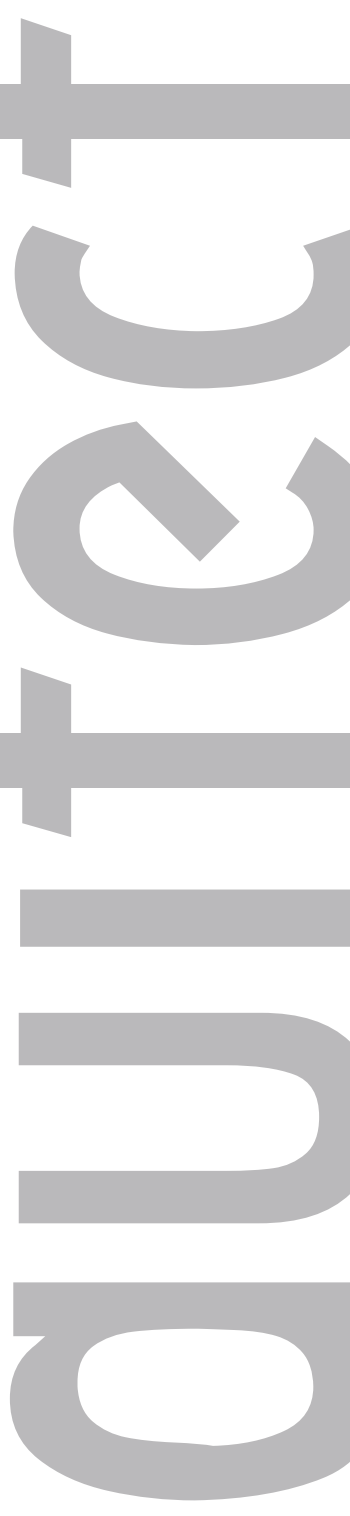

Vol. 


\section{Índice de caminabilidad para la ciudad de Bogotá \\ $\infty \quad$ Walkability index for the city of Bogotá \\ ن Índice de caminhabilidade para a cidade de Bogotá \\ Julián Alberto Gutiérrez-López \\ Yolanda Beatriz Caballero-Pérez
Rubén Alejandro Escamilla-Triana}

Principios, criterios y propósitos de desarrollo sustentable para la $\bar{\Upsilon}$ redensificacion en contextos urbanos informales

Principles, criteria and purposes of sustainable development for

re-densification in unplanned urban context

Princípios, critérios e propósitos de desenvolvimento sustent

Fabián Adolfo Aguilera-Martínez

Fabián Alonso Sarmiento-Valdés

Complejidad y constructivismo en la nueva tradición de la arquitectura de la posguerra

Complexity and constructivism in the new tradition of post-war architecture

U Complexidade e construtivismo na nova tradição da arquitetura do pósguerra

Francisco Javier Fuentes-Farías

Conservación del arte contemporáneo. El caso de Mathias Goeritz en la Catedral Metropolitana de México

Conservation of contemporary art: The case of Mathias Goeritz in the

$\varangle \quad$ Metropolitan Cathedral of Mexico

Conservação da arte contemporânea: o caso de Mathias Goeritz na Catedral Metropolitana do México

\section{Alberto Cedeño-Valdiviezo}

Pablo Torres-Lima

Operando desde la forma: un procedimiento para la valoración de la vivienda colectiva

On Operating based on form: A procedure for the valuation of collective housing

U Operando a partir da forma: um procedimento para avaliar a moradia coletiva

\section{Julián Camilo Valderrama-Vidal}

Disponibilidad de las técnicas constructivas de habitación en

ن Availability of timber housing construction techniques in Brazil

U. Disonibilidade das técnicas construtivas de moradia em madeira no Brasil

\section{Victor A. De Araujo}

Carlos M. Gutiérrez-Aguilar

Juliana Cortez-Barbosa

Maristela Gava

losé N. Garcia

Diseño y construcción de un paraguas plegable

Design and construction of a folding umbrella for architectural spaces

ن Desenho e construção de um guarda-chuva dobrável para espaços arquitetônicos

Carlos César Morales-Guzmán

Envolventes eficientes. Relación entre condiciones ambientales, espacios confortables y simulaciones digitales

(j) Efficient building envelopes: Relationship between environmental conditions,

U. comfortable spaces, and digital simulations

Envolventes eficientes: relação entre condições ambientais, espaços confortáveis e simulações digitais

Natalia Medina-Patrón

Jonathan Escobar-Saiz

(Re)pensando el enfoque tecnológico: el caso del Centro

Experimental de la Vivienda Económica (CEVE) en Argentina

ㅇ $(\mathrm{Re})$ thinking the technological approach: The case of the Experimental Center

으 for Economic Housing (CEVE) in Argentina

ن (Re)pensando a abordagem tecnológica. O caso do Centro Experimental da

Moradia Econômica na Argentina

Gustavo Pelegrin

Laila Fleker

Aurelio Ferrero 